\title{
1 Pearlite Transformation in a deformed TRIP/TWIP austenitic Steel
}

2

3

4

5

6

\section{Abstract}

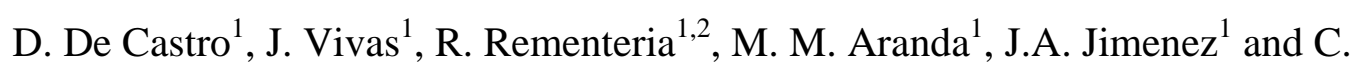

$$
\text { Capdevila }^{1 \bullet}
$$

${ }^{1}$ Centro Nacional de Investigaciones Metalúrgicas (CENIM), Consejo Superior

${ }^{2}$ Additive Manufacturing - New Frontier; ArcelorMittal Global R\&D; Calle Marineros

4, E 33490, Avilés, Asturias, Spain

The increasing population of defects in strained austenite not only increases the heterogeneous nucleation site density for pearlite transformation, but also increases the austenite free energy due to the strain. This fact leads to a reduction in the critical free energy for pearlite nucleation, which triggers pearlite formation as compared to austenite transformation without straining. Besides, a significant refinement of the pearlite colony size due to hard impingement between neighboring colonies is achieved.

Keywords: Pearlite transformation; TRIP/TWIP steel; grain refinement; pearlite spherodization; medium manganese steel

Pearlite transformation has been widely studied in the last century and is one of the most well-known microstructures of steel [1-3]. According to the classical nucleation theory [4], nucleation of pearlite starts with a nucleus of ferrite or cementite in a grain

\footnotetext{
• Correspondence: ccm@cenim.csic.es; Tel.: +34-91-553-89-00 (204); Fax: +34-91-534-74-25
} 
boundary or an inclusion [5], and then a cementite or ferrite nucleus forms adjacent to the primary nucleus with a specific orientation relationship. Ferrite and cementite arrange themselves in a cooperative manner that results in alternate ferrite and carbide lamellae maintaining a crystallographic orientation relationship, which grow sidewise and edgewise to take over the austenite grain. Grain boundaries and inclusions act as nucleation sites due to the reduction of the energy necessary for nucleation by the

31 destruction of the interface between these and the adjacent lattice. In the same way, other lattice defects such as twins or deformation bands contribute to the reduction of the energy for nucleation by the removal their interface [6]. However, just a few studies

34 focus on these nucleation sites and their effect on pearlite transformation. Furuhara et al [7] studied the effect of slight warm deformation of austenite prior to 36 pearlite transformation, concluding that deformation effectively accelerates the intragranular nucleation of pearlite even if intragranular pearlite is hardly formed without deformation. Additionally, the authors observed that $\mathrm{MnS}$ particles activate as intragranular nucleation sites of pearlite.

40 Umemoto et al [8] studied the effect of warm rolling of austenite in pearlite 41 transformation and concluded that deformation accelerates pearlite transformation.

42 Besides the increase in the austenite grain surface area per unit volume by the elongation of grains, the authors suggested the possibility that twins or deformation

44 bands generated during warm rolling act as potential nucleation sites for pearlite. This last work was carried out in steels with chemical composition that hinder austenite 46 at room temperature, and hence the effect of stain in austenite reported correspond to 47 indirect determination techniques. By contrast, the work presented here is carried out in 48 a TRIP/TWIP steel (chemical composition is listed in Table 1) where austenite is stable 49 at room temperature. The steel studied here is related with the so-called lightweight 
steels (Fe-Mn-Al-C system), which have received much attention by the scientific community given their potential for use in automotive sector [9-11]. In this context, the aim of this work is to deepen into the effect of austenite straining on pearlite transformation, in terms of kinetics and morphology, under different levels of prior austenite deformation.

The steel is casted and hence is hot-forged at $1050{ }^{\circ} \mathrm{C}$ to avoid the solidification microstructure. Hot forging at this temperature enhance the grain recrystallization promoting the formation of a very coarse austenitic grain of $250 \mu \mathrm{m}$ in average diameter. The microstructure of the steel is fully austenitic at room temperature as indicated in the XRD spectrums shown in Fig. 1(a). XRD measurements were performed by means of a Bruker AXS D8 diffractometer equipped with a Co-K $\alpha$ X-ray tube with Goebel mirror optics and a LynxEye linear position sentitive detector for ultra-fast XRD measurements. Diffraction patterns were analyzed by Rietveld refinement using the TOPAS 4.2 software, where the crystallographic information of each phase was obtained from Pearson's crystal structure database for inorganic compounds.

Cylindrical samples of $5 \mathrm{~mm}$ in diameter and $4 \mathrm{~mm}$ in length were subjected to different levels of deformation in a $100 \mathrm{kN}$ capacity electromechanical testing machine (Microtest EM2/FR) at a crosshead speed of $0.2 \mathrm{~mm} / \mathrm{min}$ (polytetrafluoroethylene

69 sheets of $75 \mu \mathrm{m}$ in thickness are placed between the specimen and the plates to reduce 70 friction and the related barreling effect). The levels of deformation achieved were 15, 35,50 and $70 \%$ reduction in-length. These were calculated as the ratio between the initial height and the crosshead displacement corrected to the compliance with standard for compression tests. 

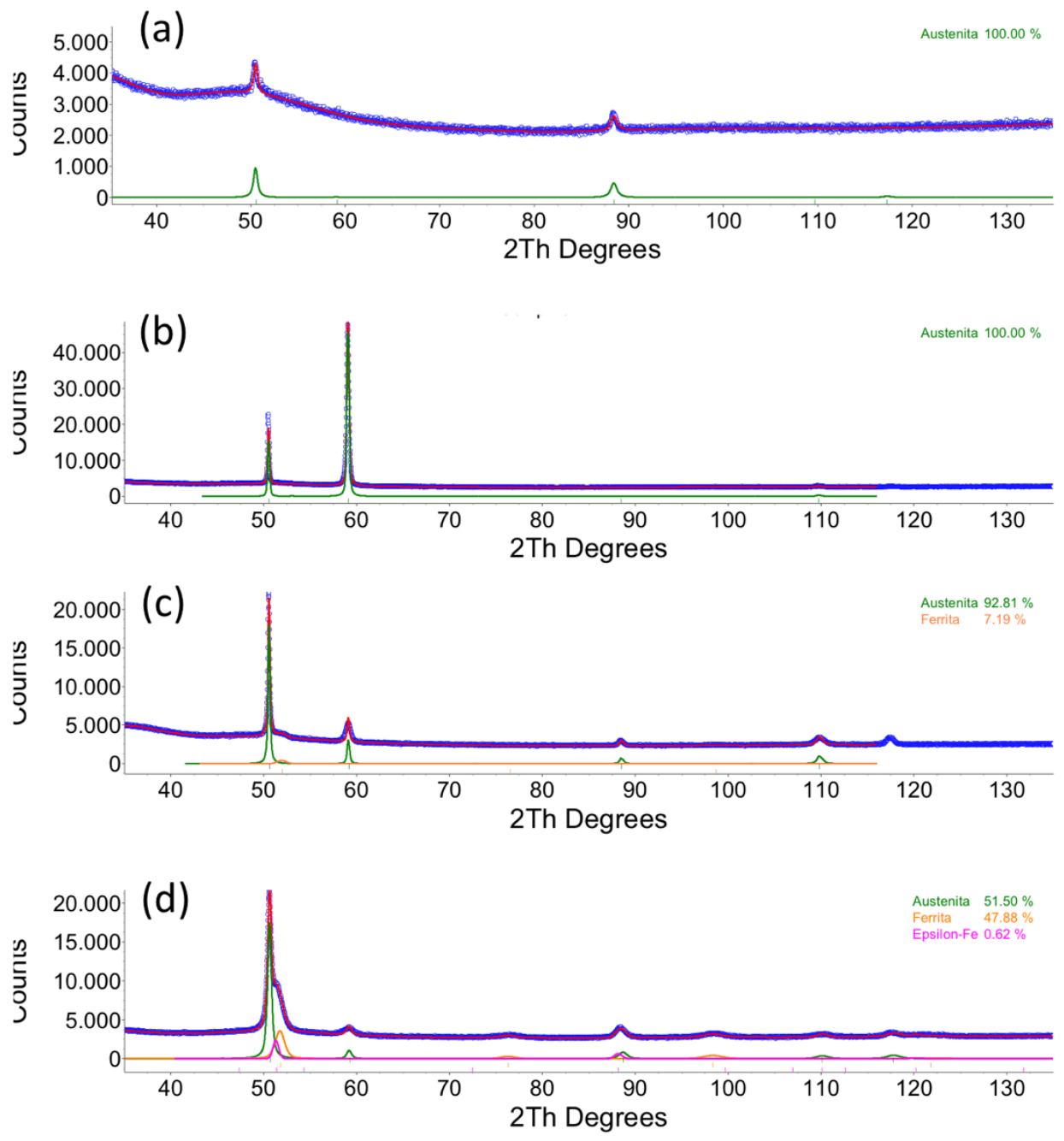

Figure 1: XRD spectrums of (a) As-received microstructure; (b) after 15\% deformation, (c) after 35\% deformation, and (d) after $70 \%$ deformation

76 Figure 2 shows optical micrographs of austenite without deformation. Samples for

77 metallographic observation were cut in half by a plane that include the compression

78 direction. After standard metallographic preparation, a $2 \%$ Nital solution was used to

79 reveal the microstructure in light optical microscopy. Figure 2 (a) and deformed at $15 \%$,

$8035 \%, 50 \%$ and $70 \%$ (Figure 2 (b), 1 (c), 2 (d) and 2 (e), respectively). 


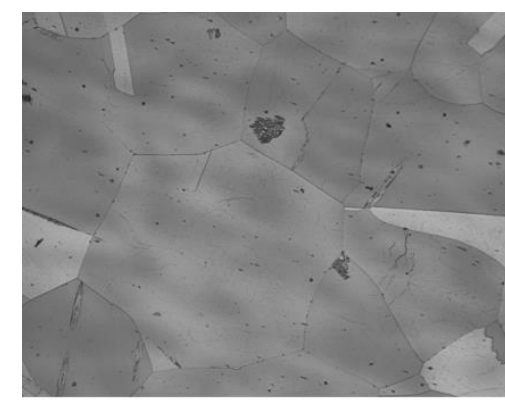

(a)

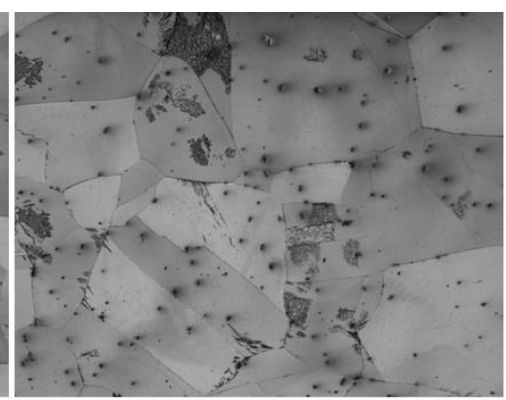

(b)

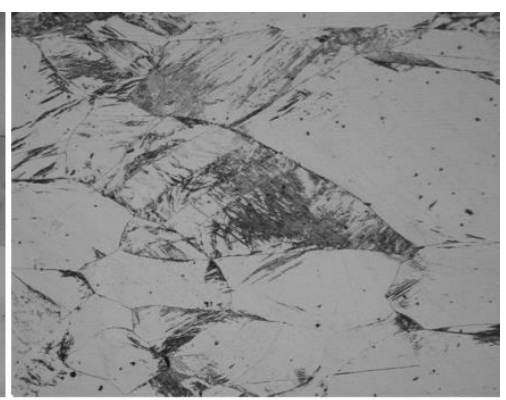

(c)

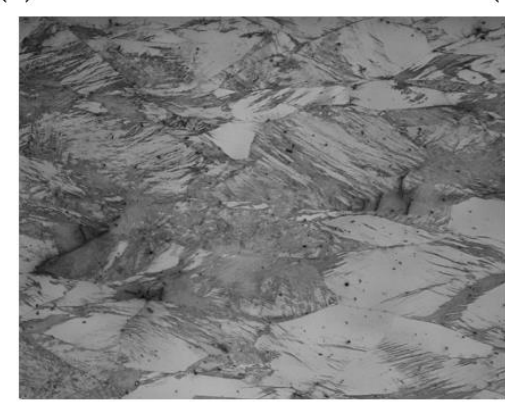

(d)

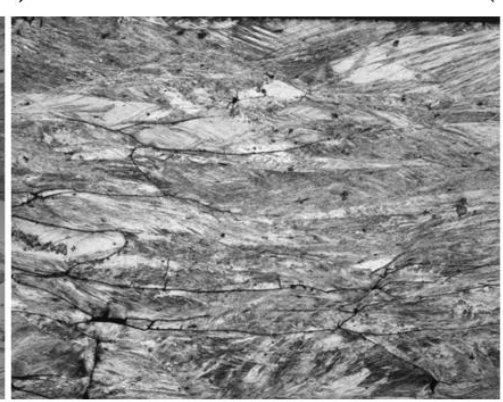

(e)

Figure 2. Initial microstructure (a) and microstructure obtained after deformation at $15 \%$ (b), $35 \%$ (c), $50 \%$ (d) and $70 \%(e)$.

82

83 Prior to deformation, the microstructure is fully austenitic with equiaxed grains. A grain 84 size of $450 \pm 50 \mu \mathrm{m}$ (equivalent diameter) was determined directly on optical 85 micrographs. By increasing the deformation to $15 \%$, some twins, but mainly 86 deformation bands are promoted in the microstructure. This is more clearly illustrated in

87 Fig. 3. This figure shows optical micrographs highlighting the increase in the amount of 88 deformation bands and twins in the microstructure after $35 \%$ deformation. 


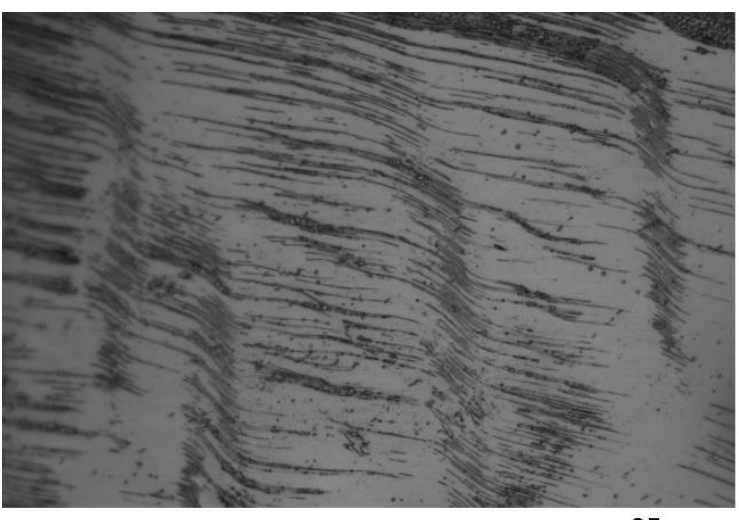

(a)

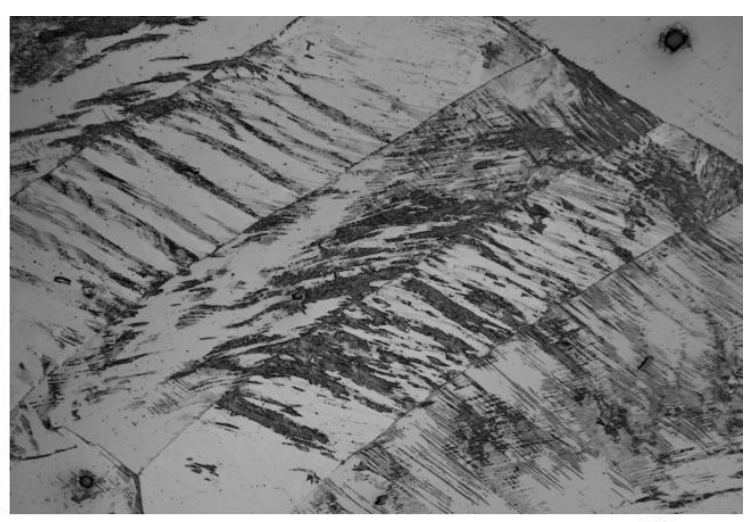

(b)
$50 \mu \mathrm{m}$

Figure 3. Deformation bands (black arrows) (a) and twins (white arrows) (b) promotes in the austenitic microstructure by deformation at $35 \%$.

91 The morphology of the grain size also changes with deformation, lengthening

92 perpendicularly to the direction of compression. Table 2 lists the quantitative results for each condition i.e., the aspect ratio of the austenite grains, the volume fractions of austenite and deformation induced martensite and the microstrain in austenite.

Assuming a direct relation between lattice defects and microstrain in austenite, quantitative X-ray diffraction (XRD) analyses were used to determine the related

97 microstrain. The spectrums collected are shown in Figure 1. As shown in Table 2, microstrain of austenite increases as deformation is raised. However, for deformation levels above the $35 \%$, deformation induced martensitic transformation also occurs.

100 The volume percent of martensite induced by deformation in each sample was

101 quantified by XRD. Table 2 reveals that the higher the level of deformation, the higher

102 the volume percent of martensite. For the lowest level of deformation (15\%) no

103 martensite was detected in the XRD diffractogram (see Figure 1(b)), although the

104 microstructure shows local traces of martensite (see Figure 2(b)), whose presence is

105 below the 3\%, which is the XRD experimental error. 
106 An isothermal heat treatment in the pearlitic field were carried out in a Carbolite CTF

107 12/65/550 furnace at $550{ }^{\circ} \mathrm{C}$ for 1 hour followed by quenching in water in a sample

108 previously deformed at $35 \%$. Figure 4 (a) shows the pearlitic microstructure obtained,

109 revealing also the presence of martensite. The martensitic nature of the features

110 observed in Fig 4(a) is consistent with the Electron backscatter diffraction (EBSD)

111 analysis shown in Figure 4(b). EBSD maps were collected at an acceleration voltage of

$11220 \mathrm{kV}$ and collected using a CRYSTAL detector of Oxford Instruments mounted in a

113 SEM JEOL JSM6300 microscope. EBSD maps were generated in areas of about

$114346 \times 282 \mu \mathrm{m}^{2}$ at step sizes of $0.45 \mu \mathrm{m}$. The indexation of the Kikuchi lines and the

115 determination of the orientations were done with the software CHANNEL 5 developed

116 by HKL Technology. Figure 4(b) shows an IPF map where body-centered cubic (bcc)

117 martensite is represented by red pixels, and face-centered cubic (fcc) austenite is

118 represented by blue pixels. Additionally, Figure 4(c) shows the microstructure obtained

119 after heat treatment of the area shown in Figure 4(a), consisting of pearlite (dark etching

120 areas) tempered martensite (light etching regions) and a mixture of austenite and fresh

121 martensite (white etching areas). Besides, Figure 4(d) shows details of the tempered

122 martensite microstructure.

123 


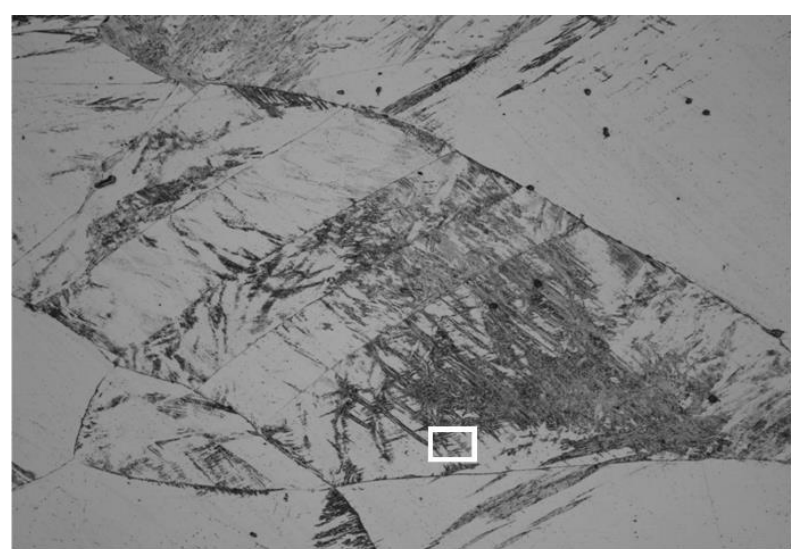

(a)

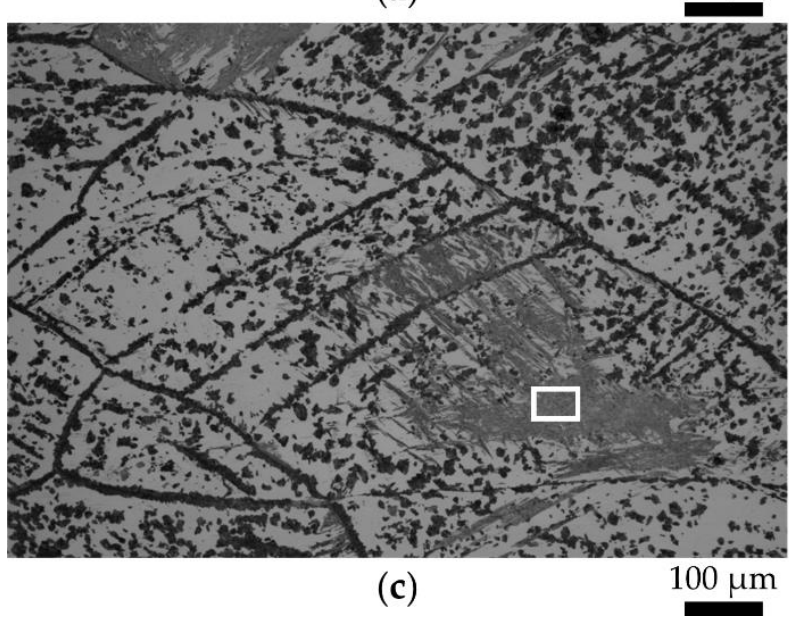

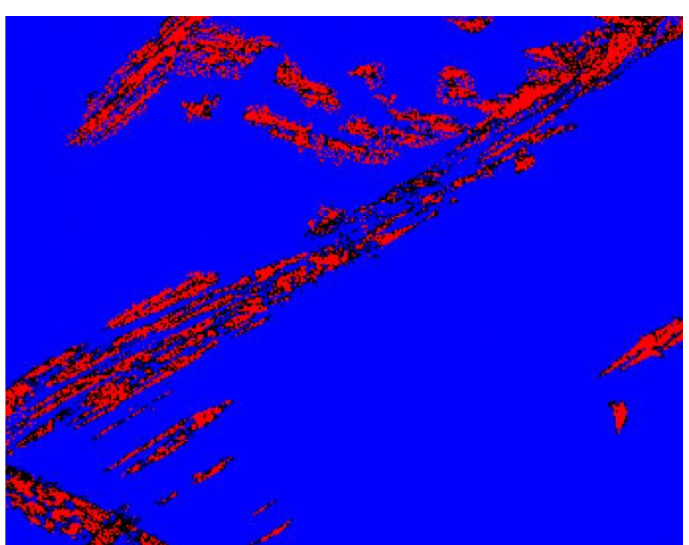

(b)

$20 \mu \mathrm{m}$

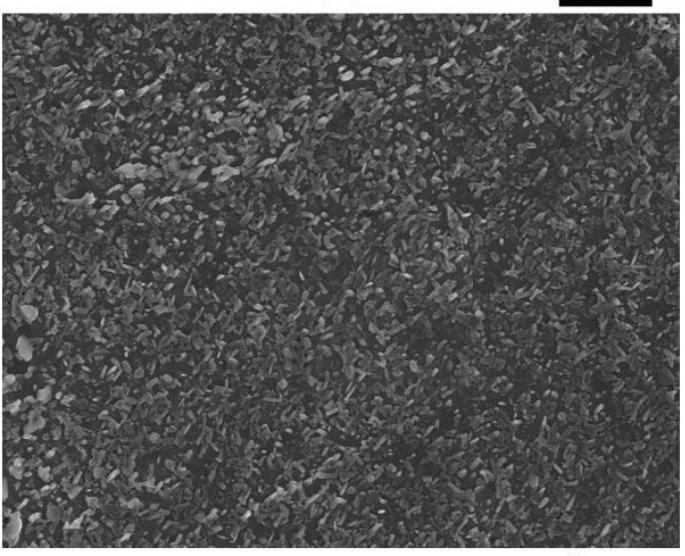

(d)

$1 \mu \mathrm{m}$

Figure 4. a) Austenitic and martensitic microstructure after deformation at 35\%, b)

EBSD Phase map. Red places represent BCC phase and blue places represent FCC

phase. EBSD map was carry out in a samples deformed at $35 \%$ with an step size of 0.45 $\mu \mathrm{m}$, c) same place of the microstructure a) after an isothermal treatment at $550^{\circ} \mathrm{C}$ for 1 hour in the pearlite field. d) SEM micrography of the tempered martensite obtained after the isothermal treatment.

125 Figure 5 demonstrates the role that the different lattice defects present in austenite have

126 in pearlite transformation. This figure shows an example of pearlite nucleated at both

127 twins and deformation bands. The decoration of austenite grain boundaries with pearlite

128 nodules is complemented with the intragranular nodules formed at lattice defects. 


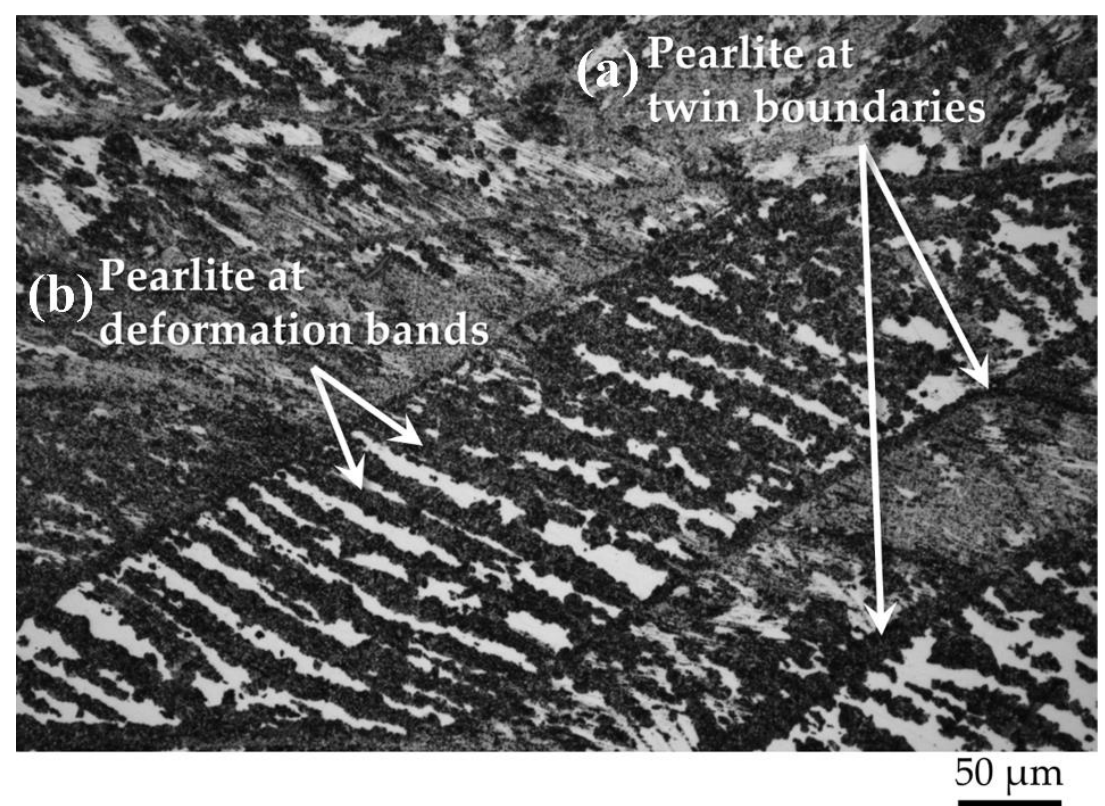

Figure 5. Pearlite nucleated in a twin (a) and deformation bands (b)

131 Figure 6 shows optical micrographs of the samples transformed at $550{ }^{\circ} \mathrm{C}$ for 36 hours

132 without prior deformation (Figure 6(a)) and deformed at 15\%, 35\%, 50\% and 70\%

133 (Figure 6(b), 6(c), 6(d) and 6(e), respectively). The white etching areas correspond to

134 austenite and/or fresh martensite, dark etching areas correspond to pearlite, and light

135 etching areas correspond to tempered martensite.

136 It is easy to see that the area percent of pearlite increases with the increase in the degree

137 of deformation. The area fraction of pearlite was evaluated on optical micrographs by

138 point counting method according to ASTM E562-02. For the sample deformed at 35\%,

139 tempered martensite regions were distinguished of pearlite by metallographic

140 procedures, and were therefore avoided in the evaluation of the pearlite area percent.

141 For high levels of deformation (50\% and 70\%) tempered martensite and pearlite areas

142 are interlocked, which makes it difficult to distinguish pearlite and determine its amount

143 by optical microscopy. Therefore, these two conditions were excluded from the study. 


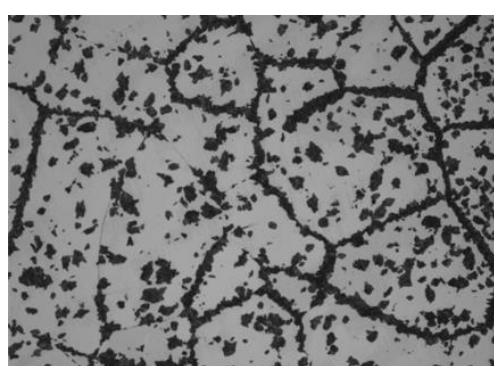

(a)

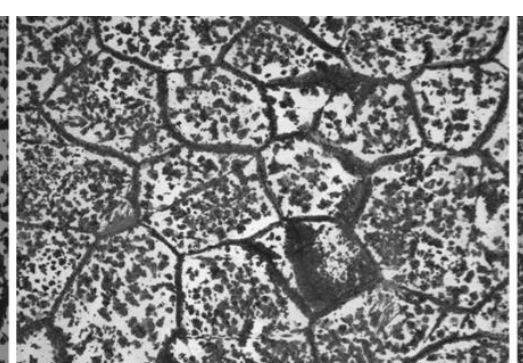

(b)

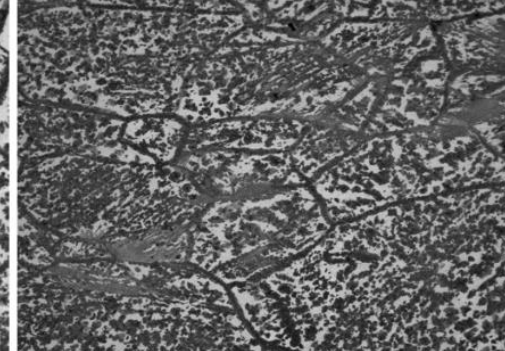

(c)

$200 \mu \mathrm{m}$

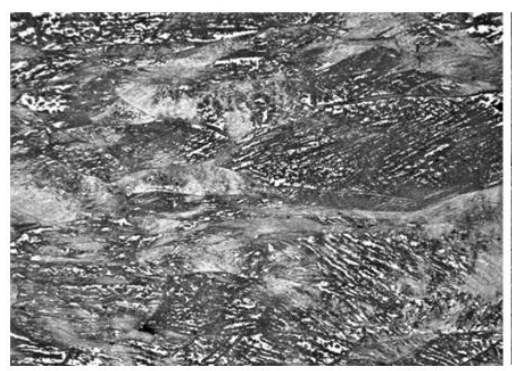

(d)

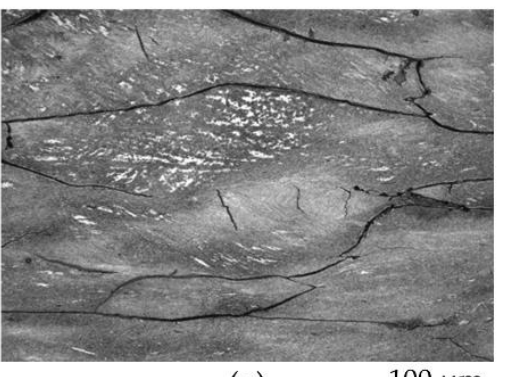

(e)

$100 \mu \mathrm{m}$

Figure 6. Optical micrographs of the sample transformed at $550^{\circ} \mathrm{C}$ for 36 hours without previous deformation (a) and the samples previously deformed at $15 \%, 35 \%, 50 \%$ and $70 \%$ (b, c, d and e respectively)

146 Figure 7(a) shows the total area percent of pearlite as a function of the previous

147 deformation in austenite. Here, the higher the prior deformation of austenite is, the

148 higher the volume fraction of pearlite obtained for the same isothermal heat treatment.

149 The grain boundaries are, in all cases, covered by pearlite nodules. The evolution with

150 time of the size of these nodules is similar in all the samples, indicating that kinetics of

151 pearlite growth is not accelerated by prior austenite deformation. However, there is an

152 increase in the fraction of intragranular pearlite with the increase in the degree of the 153 deformation. 


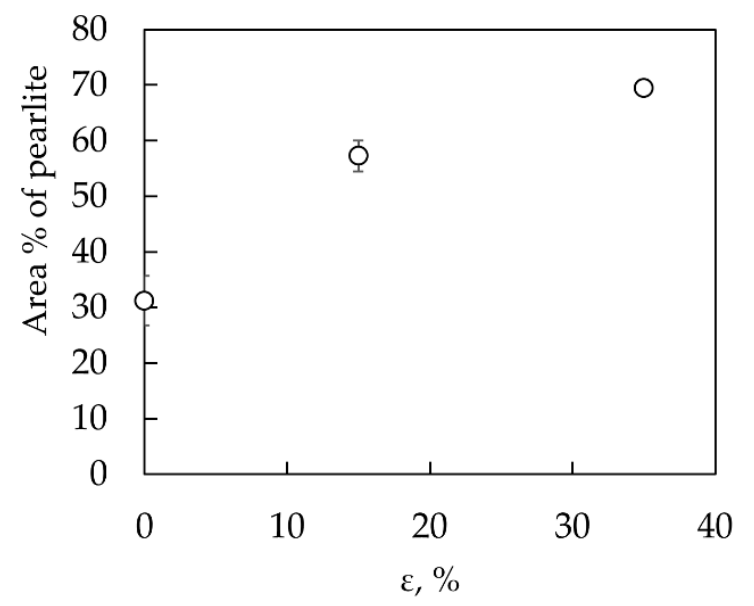

(a)

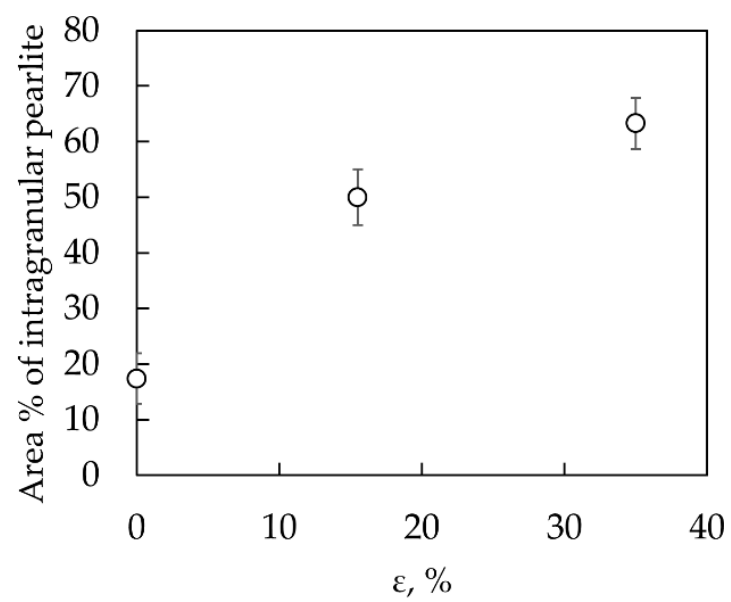

(b)

Figure 7. (a) Total area fraction of pearlite, and (b) area fraction of intragranular pearlite as a function of the deformation.

156 The fraction of intragranular pearlite was measured on optical micrographs using

157 ImageJ software, excluding pearlite nucleated at grain boundaries and tempered

158 martensite regions. Figure 7(b) shows the area fraction of intragranular pearlite as a

159 function of deformation of the austenite. The size of intragranularly formed pearlite

160 nodules presents a similar evolution with time as that of the size of pearlite nodules at

161 grain boundaries. Nevertheless, the number density of intragranular pearlite nodules

162 increases with the increase in the extent of prior austenite deformation.

163 The increase in the number of lattice defects, such as twins and deformation bands,

164 increases the number of nucleation sites for pearlite nodules, and hence, a higher

165 nucleation rate is obtained. In addition to increasing the density of heterogeneous

166 nucleation sites, the strain energy of the defects raises the austenite free energy, which

167 in turn leads to a specific reduction in the critical free energy for pearlite nucleation as it

168 was reported by Maalekian et al [12]. As a result, pearlite starts to nucleate earlier in

169 strained austenite as compared to pearlite nucleating in austenite without straining. 
170 The effect of the deformation in the morphology of pearlite was observed in SEM

171 micrographs. Figure 8 shows SEM micrographs of the samples transformed at $550{ }^{\circ} \mathrm{C}$

172 for 36 hours without deformation (Figure 8(a)) and previously deformed at $15 \%, 35 \%$,

$17350 \%$ and $70 \%$ (Figures 8(b), 8(c), 8(d) and 8(e), respectively).

174 The surface of pearlite colony per unit volume of pearlite colonies $\left(S_{V}^{P / P}\right)$ was measured

175 by quantitative metallography, consisting in overlapping a circumference on SEM

176 micrographs and counting the intersection with an edge of a colony (pearlite areas

177 where the lamellae have the same direction [10]) using the following equation [11]:

178

$179 \quad S_{V}^{P / P}=\frac{2 \cdot n_{r} \cdot M}{\pi \cdot d_{r}}$

180

181 Where $d_{r}$ is the diameter of the circumference, $n_{r}$ is the number of intersections with an edge of a colony and $\mathrm{M}$ is the magnification of the micrograph.

183

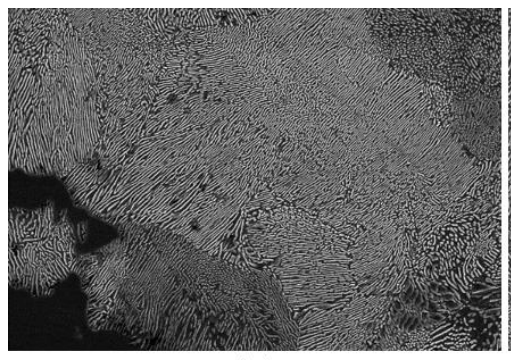

(a)

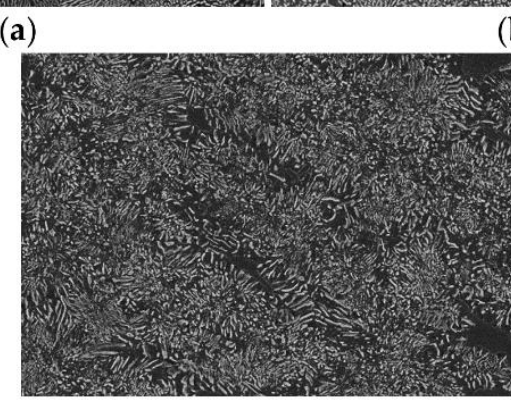

(d)

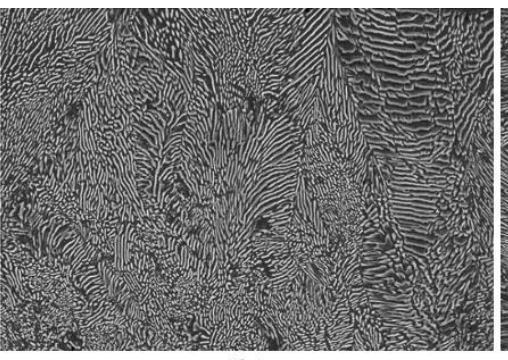

(b)

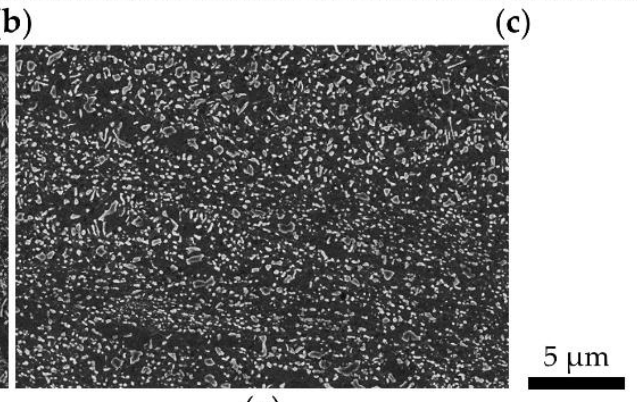

(e)

Figure 8. SEM micrograhs of pearlite colonies of the samples previously deformed at. a)

$0 \%$ b) $15 \%$ c) $32 \%$ d) $50 \%$ and e) $70 \%$. Spherodized pearlite is shown in (d) and (e). 
185 Figure 9 shows the evolution of $S_{V}^{P / P}$ as a function of deformation of the austenite for

186 the samples transformed at $550{ }^{\circ} \mathrm{C}$ for 36 hours. For high levels of deformation, the

187 austenite microstructure has a higher amount of lattice defects, and a refinement of the

188 colony size is observed. For samples deformed at $50 \%$ and $70 \%$, pearlite does not show

189 a laminar morphology, but a mixed morphology consisting in lamellar and spheroidal

190 cementite as illustrated in Figure 8(d) for the case of the sample deformed at 50\%, and

191 completely spheroidized cementite for the case of the sample deformed at $70 \%$ (Figure

$1928(\mathrm{e}))$.

193

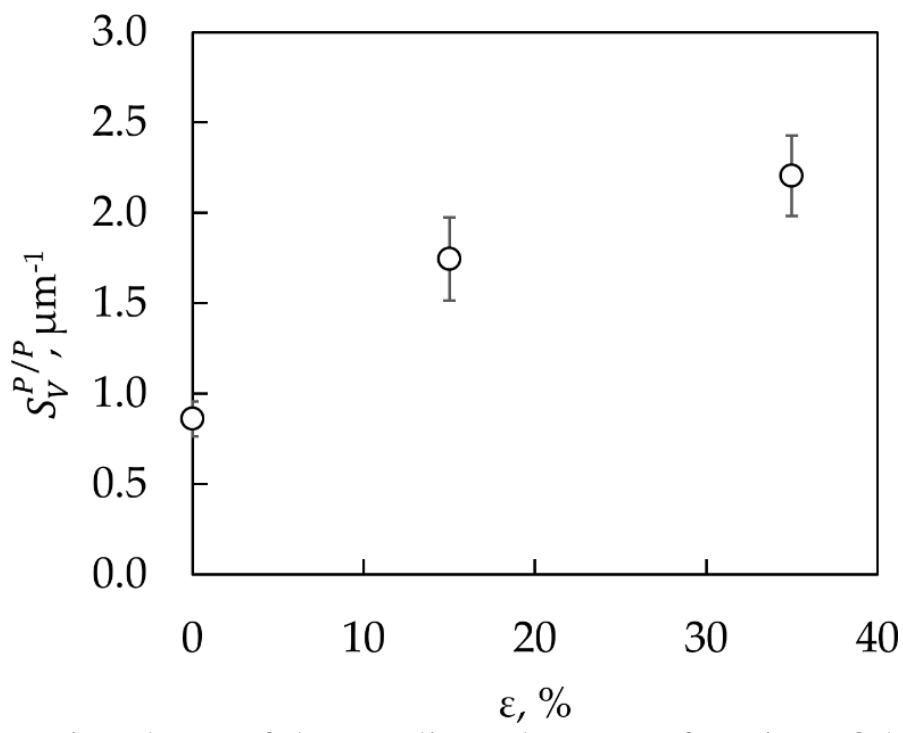

Figure 9. Area per unit volume of the pearlite colony as a function of the previous deformation

195 As aforementioned, the increase in $S_{V}^{P / P}$ suggests an increase in the number of the

196 potential nucleation sites for pearlite. Once a pearlite colony is nucleated, pearlite

197 lamellae grow until another colony growing in the opposite direction is found. At this

198 point, the clamping of both occurs (hard impingement), and the growth of the colony

199 stops. Therefore, the increase in the number of potential intragranular nucleation sites 
by increasing the density of twins or deformation bands provides a colony size

201 refinement because of the hard impingement events on growing colonies. For higher

202 levels of deformation, such hard impingement events are so abundant that pearlite

203 colonies barely grow. This results in a pearlitic microstructure formed by short lamellae

204 of pearlite or just some nucleus of pearlite whose growth was so short that its geometric

205 form is closer to that of a particle than to that of a lamellar structure, providing a

206 microstructure of spheroidized morphology.

207 We might conclude that deformation of austenite prior to pearlite transformation

208 effectively accelerates the intragranular nucleation of pearlite through the nucleation at

209 twin boundaries and deformation bands. However, the increasing population of defects

210 not only increases the density of heterogeneous nucleation sites for pearlite

211 transformation, but also increases the austenite free energy due to strain. This fact leads

212 to a reduction in the critical free energy for pearlite nucleation, which triggers pearlite

213 formation. For the case of highly strained austenite, the refinement of the pearlite

214 colony size is so high that a spheroidized morphology of pearlite is obtained.

217 Acknowledgments

218 The authors acknowledge financial support to Spanish Ministerio de Economia y

219 Competitividad (MINECO) through in the form of a Coordinate Project (MAT2016-

220 80875-C3-1-R). Authors also acknowledge financial support to Comunidad de Madrid

221 through DIMMAT-CM_S2013/MIT-2775 project.

\section{References}


[1] J. Cahn, W. Hagel. Theory of the pearlite reaction. In: Z. Zackey, H. Aaronson,

226 editors. Decomposition of Austenite by Diffusional Processes. New York: Interscience, 227 1962. p.131-192.

228 [2] M. Hillert: New York: Interscience, 1962, vol., pp. 197-237.

229 [3] N. Ridley. The pearlite reaction. In: M.A. R., G. J.I, editors. Phase

230 Transformations in Ferrous Alloys. (TMS-AIME, Warrendale, PA): Metallurgical

231 Society of AIME, 1984. p.201-236.

232 [4] F.C. Hull, R.F. Mehl: Trans. ASM, 1942, vol. 30, pp. 381-421.

233 [5] H.I. Aaronson, V.F. Zackay: Decomposition of austenite by diffusional

234 processes. Interscience Publ., 1962, p. Pages.

235 [6] P.J. Clemm, J.C. Fisher: Acta Metall., 1955, vol. 3, pp. 70-73.

236 [7] T. Furuhara, N. Kimura, T. Maki: Steel Res. Int., 2012, vol. 83, pp. 358-362.

237 [8] M. Umemoto, H. Ohtsuka, I. Tamura: Trans. Iron Steel Inst. Japan, 1983, vol. $238 \quad 23$, pp. $775-784$.

239 [9] J. Moon, S. J-. Park, J. H. Jang, T. H-. Lee, C. H-. Lee, H. U-. Hong, H. N. Han, 240 J. Lee, B. H. Lee, C. Lee: Acta Mater., 2018, vol. 147, pp. 226-235.

241 [10] J. Zhang, D. Raabe, C. C. Tasan: Acta Mater., 2017, vol. 141, pp. 374-387.

242 [11] S. Chen, R. Rana, A. Haldar, R. K. Ray: Prog. Mater. Sci., vol. 89, 345-391.

243 [12] M. Maalekian, M.L. Lendinez, E. Kozeschnik, H.P. Brantner, H. Cerjak: Mater. 244 Sci. Eng. A, 2007, vol. 454-455, pp. 446-452.

245 [13] M. Hillert. The formation of pearlite. In: V.F. Zackay, H.I. Aaronson, editors. 246 Decomposition of austenite by diffusional processes. New York: Interscience, 1962. p.197-237. 
248 [14] E.E. Underwood, J.C. Grebetz, R.A. Koos. STATISTICAL STUDY OF GRAPHITE AND PEARLITE IN NODULAR CAST IRON. Praktische Metallographie/Practical Metallography, vol. 19, 1982. p.347-355. 


\section{Figure Captions}

253 Figure 1: XRD spectrums of (a) As-received microstructure; (b) after 15\% deformation,

254 (c) after $35 \%$ deformation, and (d) after $70 \%$ deformation

255 Figure 2. Initial microstructure (a) and microstructure obtained after deformation at 15\%

256 (b), 35\% (c), 50\% (d) and 70\% (e).

257 Figure 3. Deformation bands (black arrows) (a) and twins (white arrows) (b) promotes

258 in the austenitic microstructure by deformation at $35 \%$.

259 Figure 4. a) Austenitic and martensitic microstructure after deformation at $35 \%$, b)

260 EBSD Phase map. Red places represent BCC phase and blue places represent FCC

261 phase. EBSD map was carry out in a samples deformed at $35 \%$ with an step size of 0.45

$262 \mu \mathrm{m}, \mathrm{c})$ same place of the microstructure a) after an isothermal treatment at $550^{\circ} \mathrm{C}$ for 1

263 hour in the pearlite field. d) SEM micrography of the tempered martensite obtained after

264 the isothermal treatment.

265 Figure 5. Pearlite nucleated in a twin (a) and deformation bands (b)

266 Figure 6. Optical micrographs of the sample transformed at $550^{\circ} \mathrm{C}$ for 36 hours without

267 previous deformation (a) and the samples previously deformed at 15\%,35\%, 50\% and

$26870 \%$ (b, c, d and e respectively)

269 Figure 7. (a) Total area fraction of pearlite, and (b) area fraction of intragranular pearlite

270 as a function of the deformation.

271 Figure 8. SEM micrograhs of pearlite colonies of the samples previously deformed at. a)

$2720 \%$ b) $15 \%$ c) $32 \%$ d) $50 \%$ and e) $70 \%$. Spherodized pearlite is shown in (d) and (e).

273 Figure 9. Area per unit volume of the pearlite colony as a function of the previous

274 deformation 
278 Table 1: Chemical composition (in wt\%) of TRIP/TWIP steel studied

\begin{tabular}{|l|l|l|l|l|}
\hline & C & Mn & Al & Fe \\
\hline Wt.\% & 0.63 & 9.82 & 4.60 & Balance \\
\hline
\end{tabular}

281 Table 2. Aspect ratio, volume fraction of martensite, volume fraction of austenite and 282 microstrain austenite as a function of the deformation.

\begin{tabular}{|c|c|c|c|c|c|}
\hline Deformation & $0 \%$ & $15 \%$ & $35 \%$ & $50 \%$ & $70 \%$ \\
\hline Aspect ratio & $0.77 \pm 0.09$ & $0.67 \pm 0.14$ & $0.55 \pm 0.15$ & $0.31 \pm 0.08$ & $1.54 \pm 0.42$ \\
\hline $\begin{array}{l}\text { Volume } \\
\text { fraction } \\
\text { Martensite }\end{array}$ & $0 \pm 3$ & $0 \pm 3$ & $7.2 \pm 3$ & $27.6 \pm 3$ & $47.9 \pm 3$ \\
\hline $\begin{array}{l}\text { Volume } \\
\text { fraction } \\
\text { austenite }\end{array}$ & $100 \pm 3$ & $100 \pm 3$ & $92.8 \pm 3$ & $72.4 \pm 3$ & $51.5 \pm 3$ \\
\hline $\begin{array}{l}\text { Microstrain } \\
\text { austenite }\end{array}$ & 0.035 & 0.096 & 0.12 & 0.14 & 0.24 \\
\hline
\end{tabular}



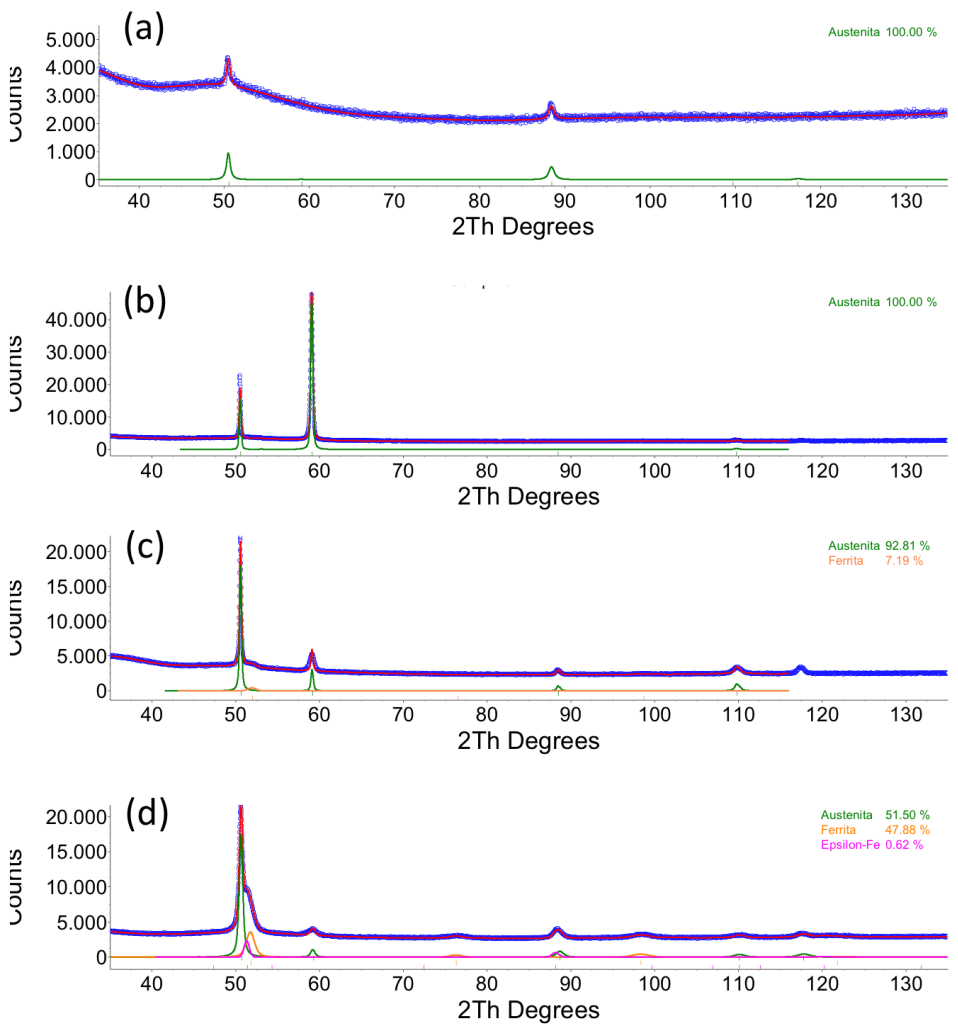


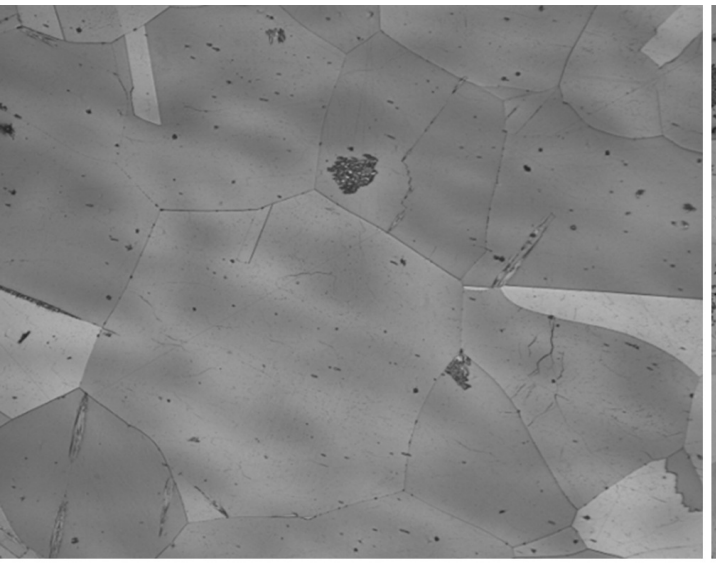

(a)

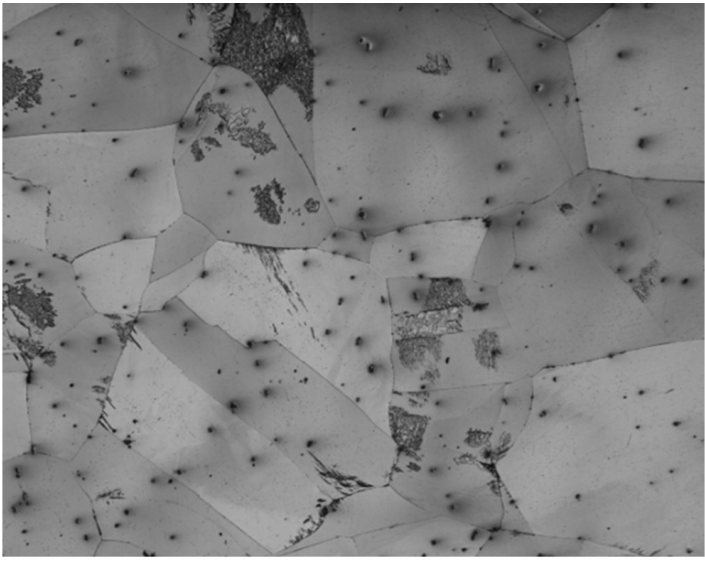

(b)

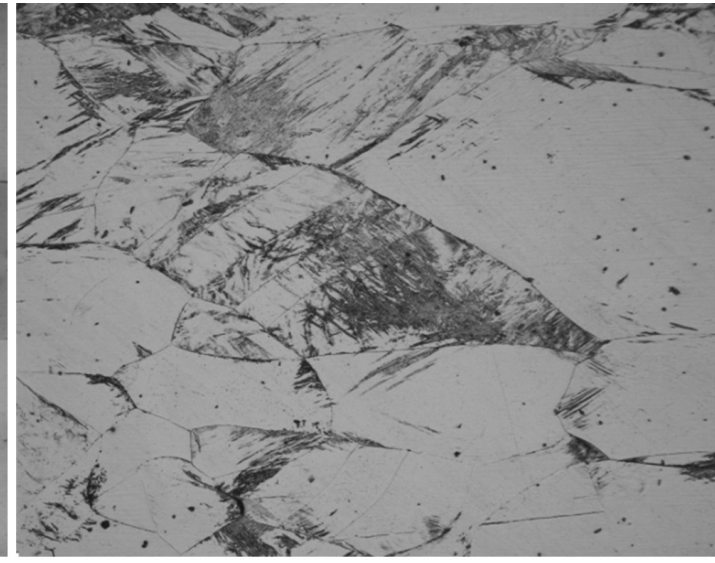

(c)

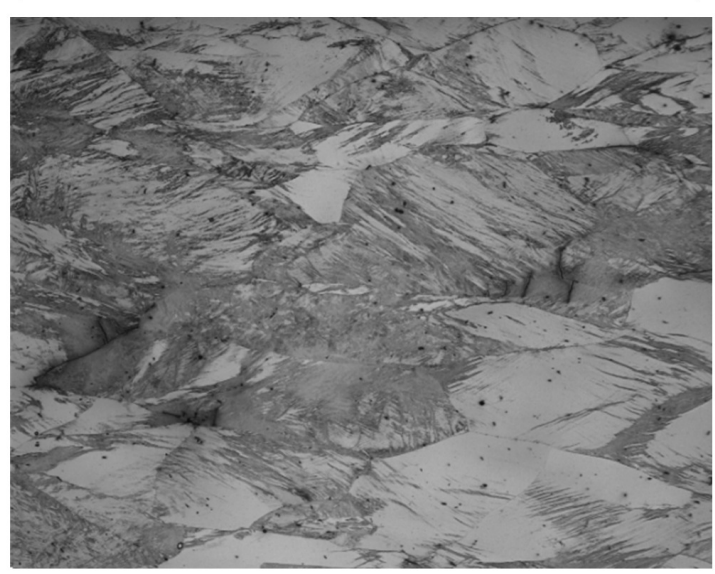

(d)

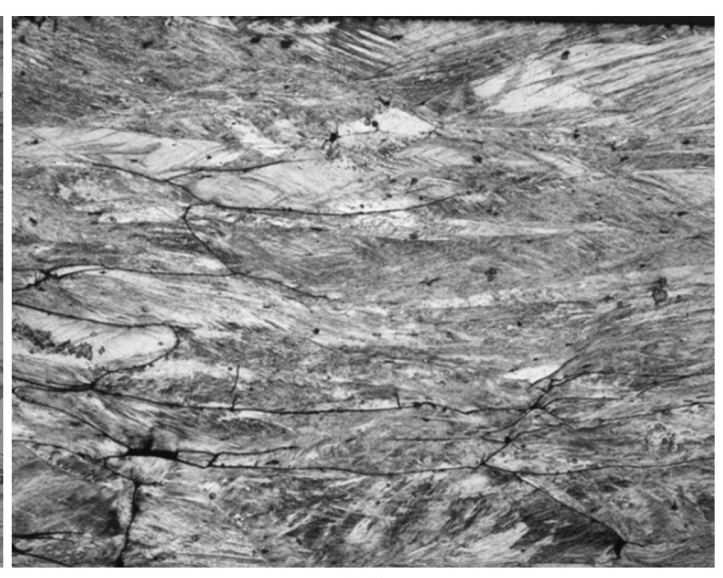

(e)
$200 \mu \mathrm{m}$ 


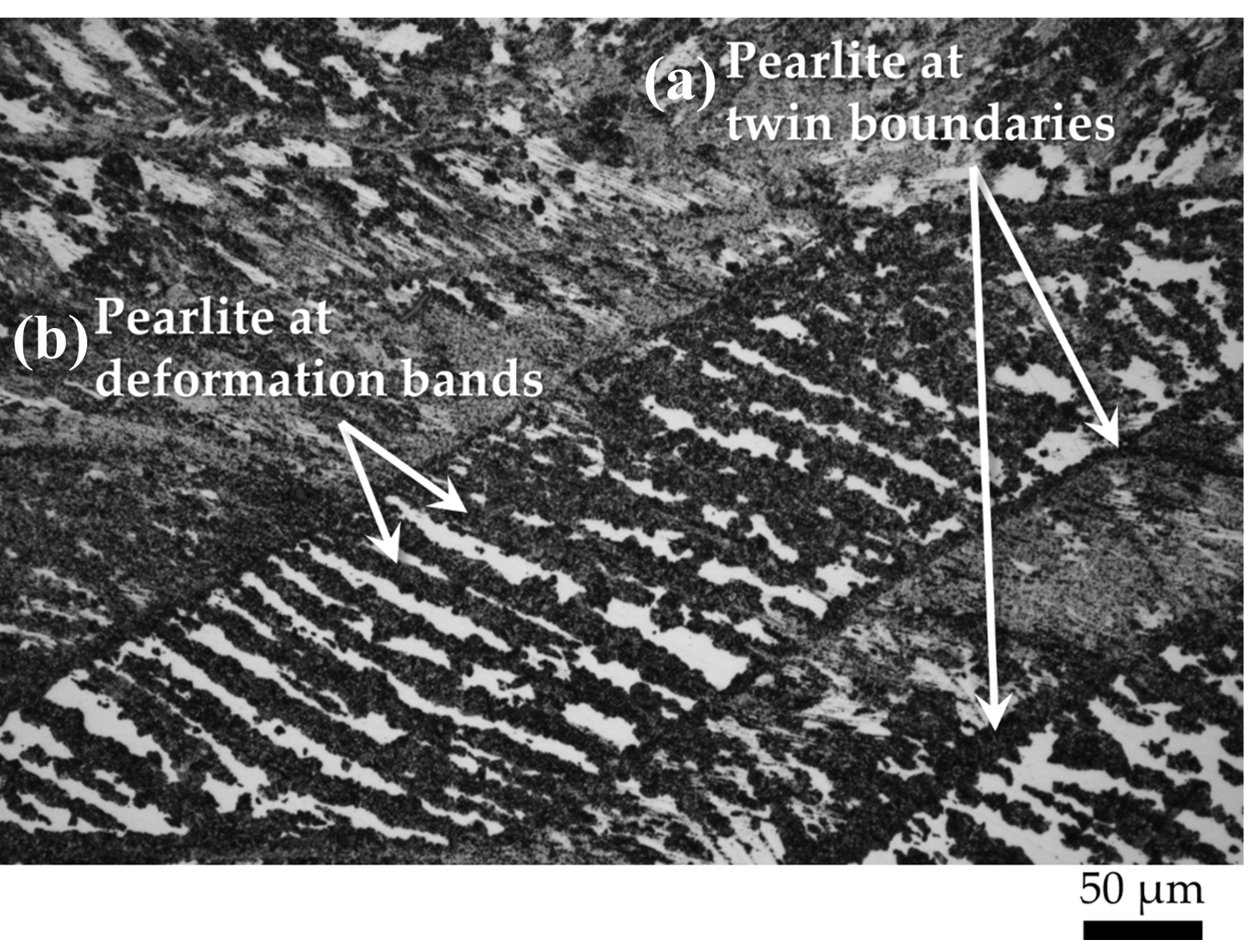




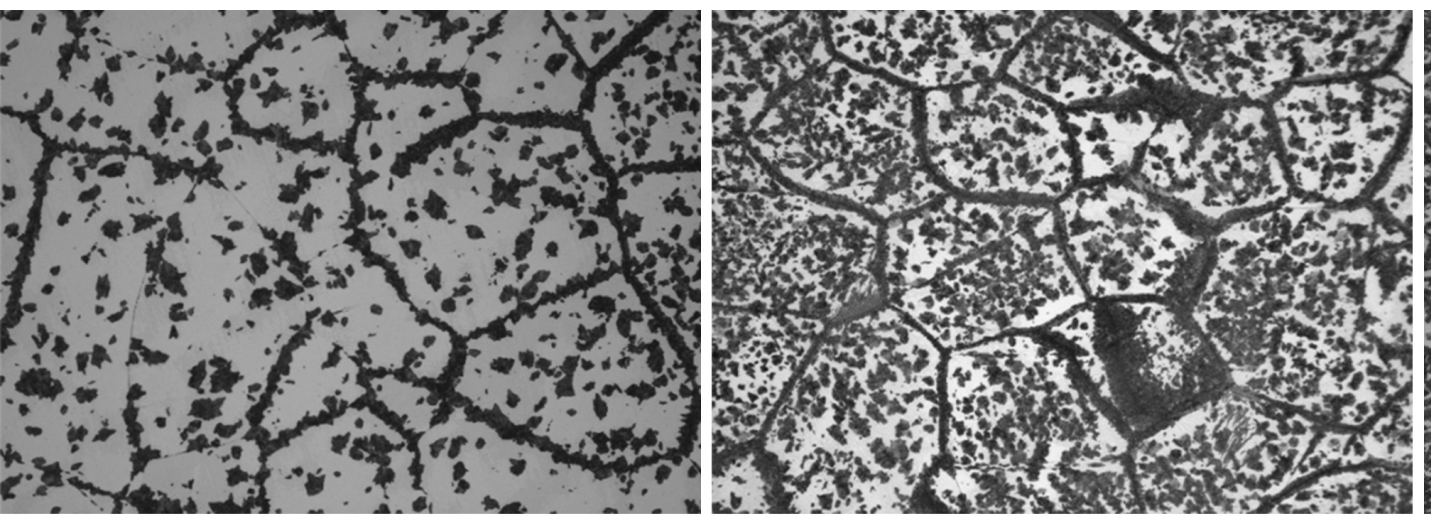

(a) (b)
$200 \mu \mathrm{m}$

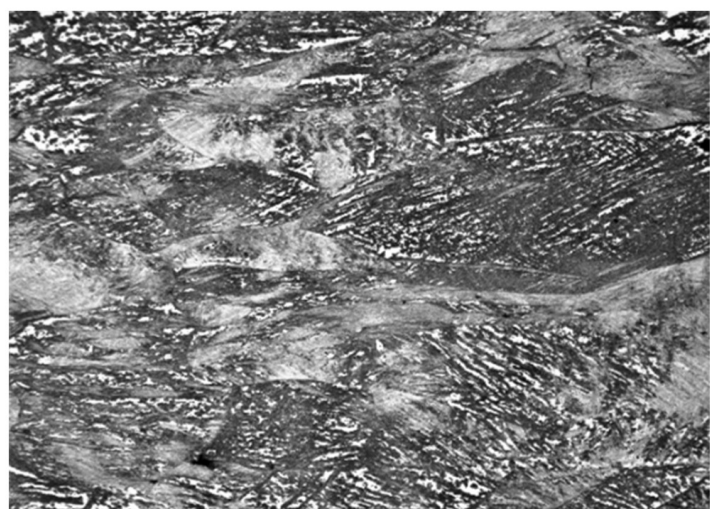

(d)

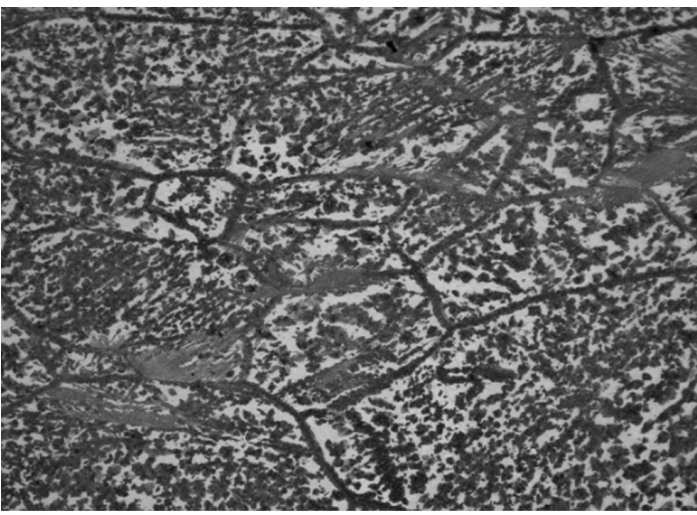

(c)

$200 \mu \mathrm{m}$

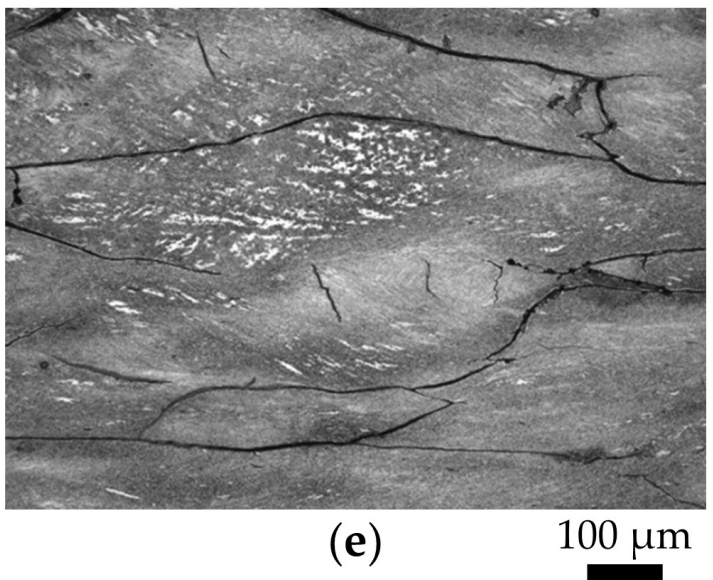




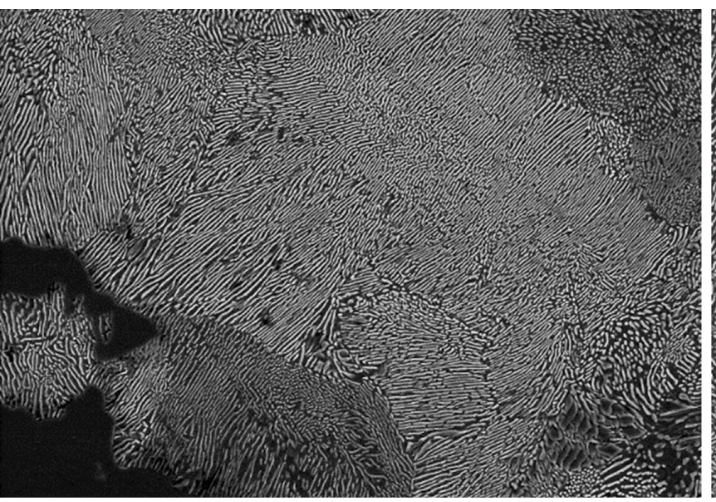

(a)

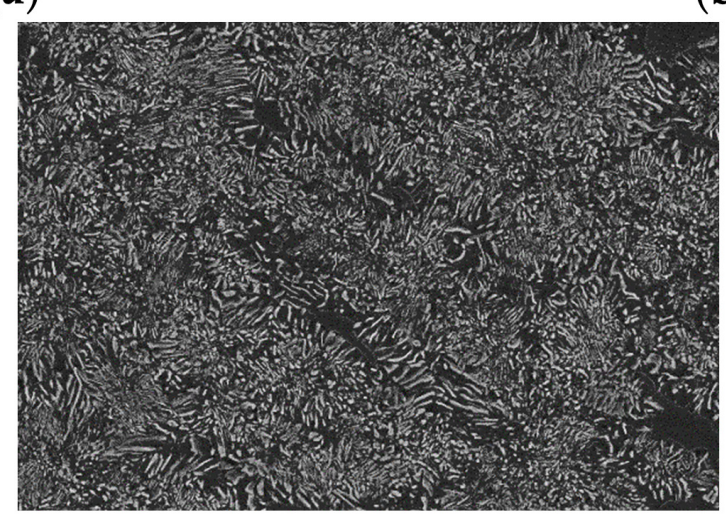

(d)

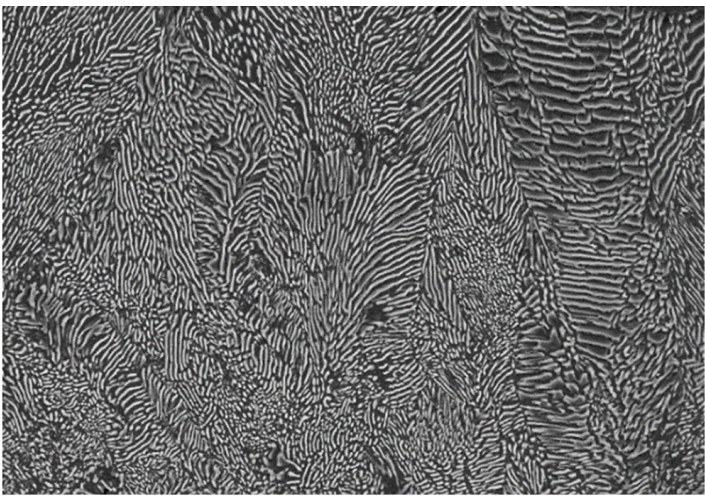

(b)

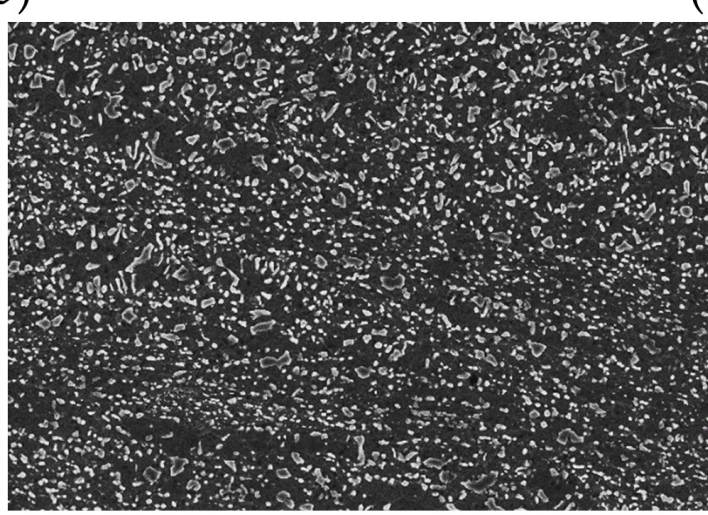

(e)

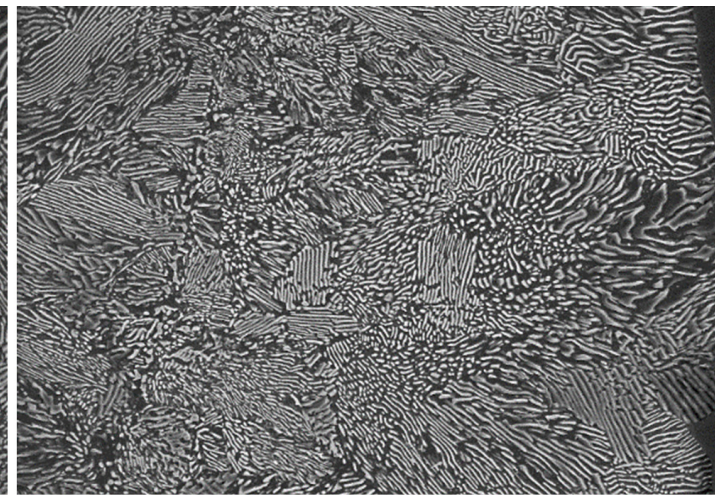

(c)

$5 \mu \mathrm{m}$ 


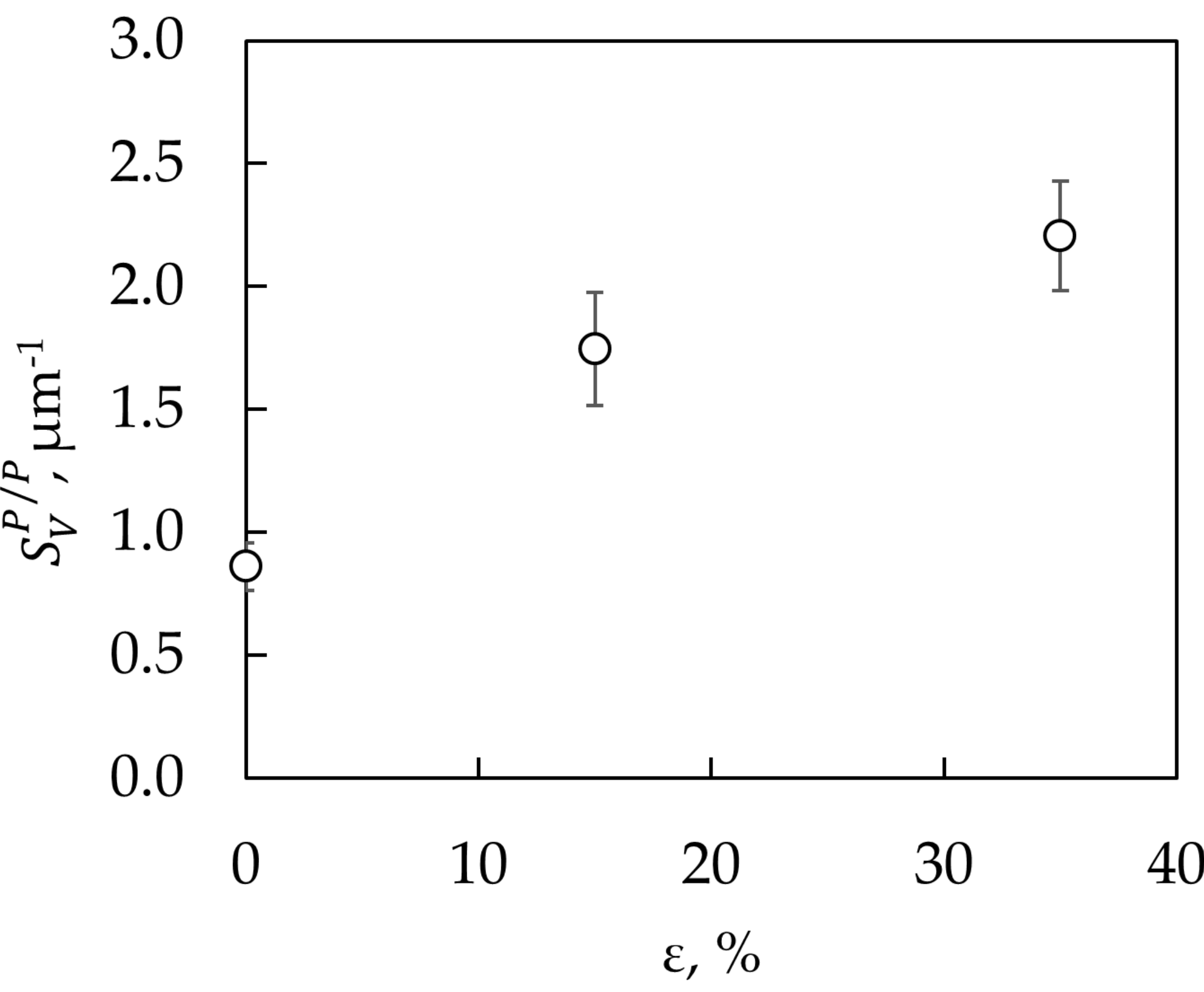


Pearlite Transformation in a deformed TRIP/TWIP austenitic Steel

2

3

4

\section{Abstract}

12 The increasing population of defects in strained austenite not only increases the

13 heterogeneous nucleation site density for pearlite transformation, but also increases the

19 Keywords: Pearlite transformation; TRIP/TWIP steel; grain refinement; pearlite
D. De Castro $\frac{1}{4}$ J. Vivas $\frac{1}{,}$, R. Rementeria $\frac{1,2}{2}$, M. M. Aranda ${ }^{1}$ J.A. Jimenez ${ }^{1}$ and and C. Capdevila ${ }^{\perp^{\bullet}}$ Investigaciones Científicas (CSIC), Avda Gregorio del Amo, 8, E 28040 Madrid, Spain

${ }^{2}$ Additive Manufacturing - New Frontier; ArcelorMittal Global R\&D; Calle Marineros

\section{4, E 33490, Avilés, Asturias, Spain}

${ }^{1}$ Centro Nacional de Investigaciones Metalúrgicas (CENIM), Consejo Superior austenite free energy due to the strain. This fact leads to a reduction in the critical free energy for pearlite nucleation, which triggers pearlite formation as compared to austenite transformation without straining. Besides, a significant refinement of the pearlite colony size due to hard impingement between neighboring colonies is achieved. spherodization; medium manganese steel

Pearlite transformation has been widely studied in the last century and is one of the most well-known microstructures of steel [1-3]. According to the classical nucleation theory [4], nucleation of pearlite starts with a nucleus of ferrite or cementite in a grain
Formatted: Superscript

Formatted: Superscript

Formatted: Superscript

Formatted: Superscript

Formatted: Superscript

Formatted: Superscript

Formatted: Superscript

\footnotetext{
• Correspondence: ccm@ cenim.csic.es; Tel.: +34-91-553-89-00 (204); Fax: +34-91-534-74-25
} 
boundary or an inclusion [5], and then a cementite or ferrite nucleus forms adjacent to

26 the primary nucleus with a specific orientation relationship. Ferrite and cementite

27 arrange themselves in a cooperative manner that results in alternate ferrite and carbide

28 lamellae maintaining a crystallographic orientation relationship, which grow sidewise

29 and edgewise to take over the austenite grain. Grain boundaries and inclusions act as

30 nucleation sites due to the reduction of the energy necessary for nucleation by the

31 destruction of the interface between these and the adjacent lattice. In the same way,

32 other lattice defects such as twins or deformation bands contribute to the reduction of

33 the energy for nucleation by the removal their interface [6]. However, just a few studies

34 focus on these nucleation sites and their effect on pearlite transformation.

35 Furuhara et al [7] studied the effect of slight warm deformation of austenite prior to

36 pearlite transformation, concluding that deformation effectively accelerates the

37 intragranular nucleation of pearlite even if intragranular pearlite is hardly formed

38 without deformation. Additionally, the authors observed that MnS particles activate as

39 intragranular nucleation sites of pearlite.

40 Umemoto et al [8] studied the effect of warm rolling of austenite in pearlite

41 transformation and concluded that deformation accelerates pearlite transformation.

42 Besides the increase in the austenite grain surface area per unit volume by the

43 elongation of grains, the authors suggested the possibility that twins or deformation

44 bands generated during warm rolling act as potential nucleation sites for pearlite.

Both works mentioned above were This last work was carried out in steels with chemical composition that hinder austenite at room temperature, and hence the effect of stain in austenite reported correspond to indirect determination techniques. By contrast, the work presented here is carried out in a TRIP/TWIP steel (chemical composition is listed in Table 1) where austenite is stable at room temperature. The steel studied here is 
related with the so-called lightweight steels (Fe-Mn-Al-C system), which have received

51 much attention by the scientific community given their potential for use in automotive sector [9-11]. In this context, the aim of this work is to deepen into the effect of

53 austenite straining on pearlite transformation, in terms of kinetics and morphology,

54 under different levels of prior austenite deformation.

55 The steel is casted and hence is hot-forged at $1050^{\circ} \mathrm{C}$ to avoid the solidification

56 microstructure. Hot forging at this temperature enhance the grain recrystallization

57 promoting the formation of a very coarse austenitic grain of $250 \mu \mathrm{m}$ in average

58 diameter. The microstructure of the steel is fully austenitic at room temperature as

59

60

61

62

63

64

65

66

67

68

69

70

71

72

73

74

indicated in the XRD spectrums shown in Fig. 1(a). XRD measurements were

performed by means of a Bruker AXS D8 diffractometer equipped with a Co-Ka X-ray

tube with Goebel mirror optics and a LynxEye linear position sentitive detector for

ultra-fast XRD measurements. Diffraction patterns were analyzed by Rietveld

refinement using the TOPAS 4.2 software, where the crystallographic information of

each phase was obtained from Pearson's crystal structure database for inorganic

compounds.

In this sense, $e$ Cylindrical samples of $5 \mathrm{~mm}$ in diameter and $4 \mathrm{~mm}$ in length were

subjected to different levels of deformation in a $100 \mathrm{kN}$ capacity electromechanical

testing machine (Microtest EM2/FR) at a crosshead speed of $0.2 \mathrm{~mm} / \mathrm{min}$

(polytetrafluoroethylene sheets of $75 \mu \mathrm{m}$ in thickness are placed between the specimen

and the plates to reduce friction and the related barreling effect). The levels of

deformation achieved were $15,35,50$ and $70 \%$ reduction in-length. These were

calculated as the ratio between the initial height and the crosshead displacement

corrected to the compliance with standard for compression tests. 


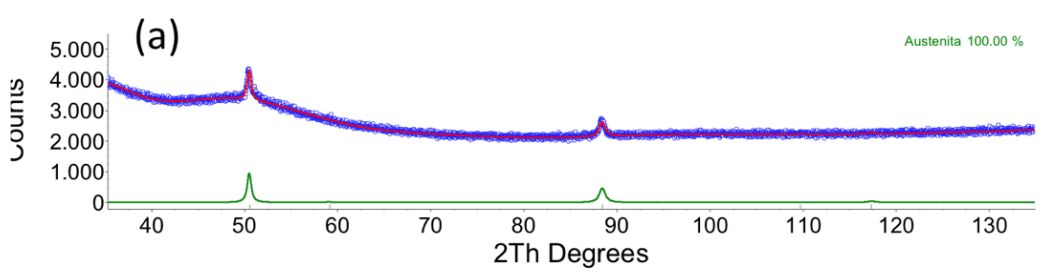

Formatted: Centered
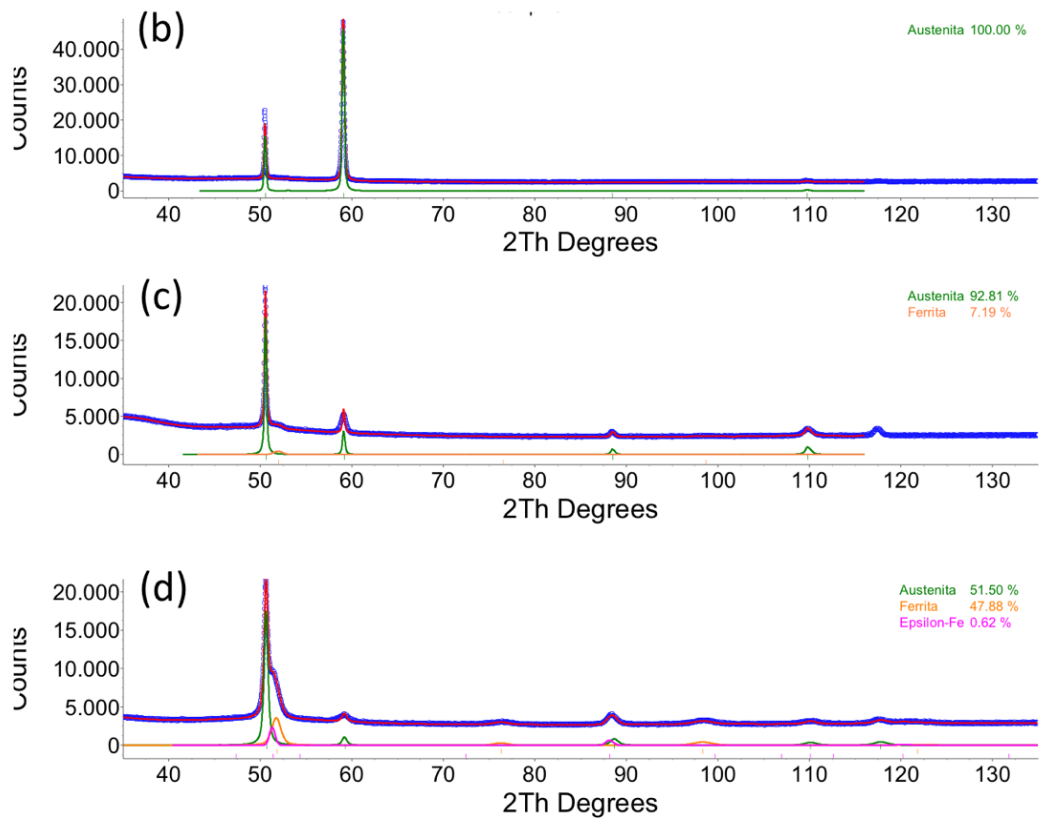

Figure 1: XRD spectrums of (a) As-received microstructure; (b) after 15\%

deformation, (c) after 35\% deformation, and (d) after 70\% deformation

81
Figure 2 shows optical micrographs of austenite without deformation. Samples for metallographic observation were cut in half by a plane that include the compression direction. After standard metallographic preparation, a $2 \%$ Nital solution was used to reveal the microstructure in light optical microscopy. Figure 2 (a) and deformed at 15\%, 35\%, 50\% and 70\% (Figure 2 (b), 1 (c), 2 (d) and 2 (e), respectively).
Formatted: Font: Not Italic 


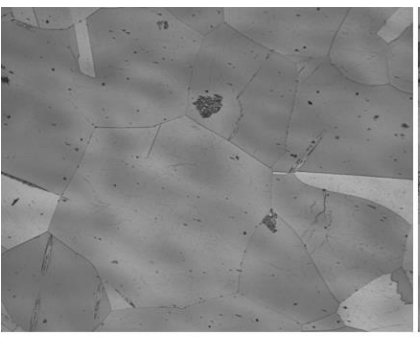

(a)

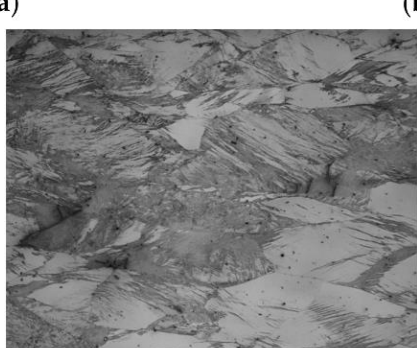

(d)

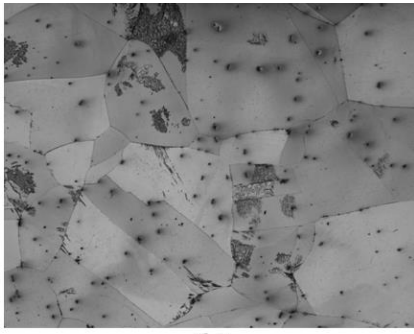

(b)

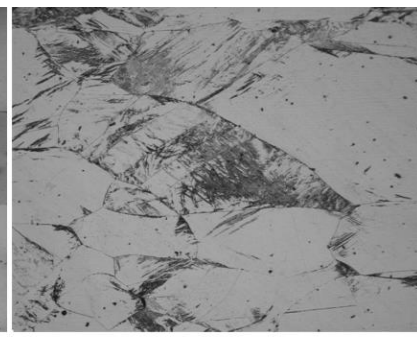

(c)

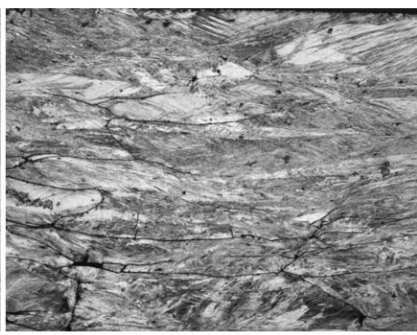

$200 \mu \mathrm{m}$

(e)

Figure 24. Initial microstructure (a) and microstructure obtained after deformation at $15 \%(\mathrm{~b}), 35 \%$ (c), $50 \%(\mathrm{~d})$ and $70 \%(\mathrm{e})$.

83

84 Figure 1 shows optical micrographs of austenite without deformation. Samples for metallographic observation were cut in half perpendicularly to the compression

86 direction. After standard metallographic preparation, a $2 \%$ Nital solution was used to reveal the microstructure in light optical microscopy. Figure 1 (a) and deformed at $15 \%$ 35\%, 50\% and 70\% (Figure 1 (b), 1 (c), 1 (d) and 1 (e), respectively).Prior to deformation, the microstructure is fully austenitic with equiaxed grains. A grain size of

$90450 \pm 50 \mu \mathrm{m}$ (equivalent diameter) was determined directly on optical micrographs. By

91 increasing the deformation to $15 \%$, some twins, but mainly deformation bands are

92 promoted in the microstructure. This is more clearly illustrated in Fig. $\underline{3} z$. This figure shows optical micrographs highlighting the increase in the amount of deformation bands

94 and twins in the microstructure after $35 \%$ deformation. 


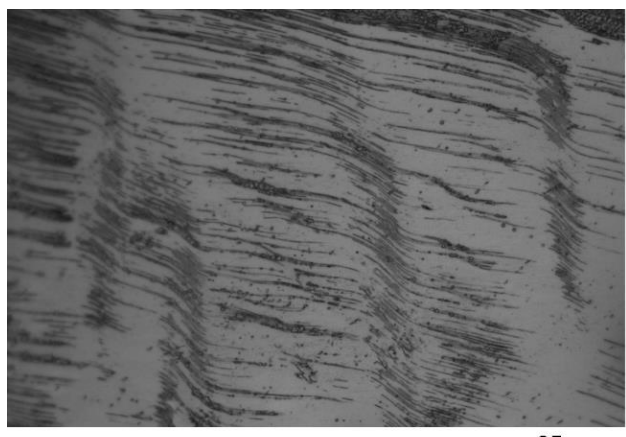

(a)

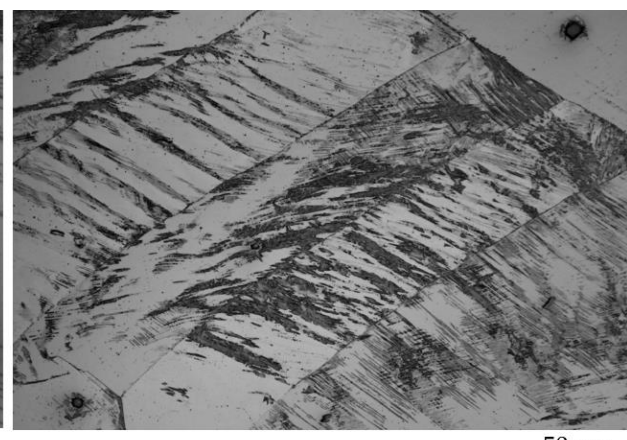

(b)

Figure $\underline{3 z}$. Deformation bands (black arrows) (a) and twins (white arrows) (b) promotes in the austenitic microstructure by deformation at $35 \%$.

96

97 The morphology of the grain size also changes with deformation, lengthening

98 perpendicularly to the direction of compression. Table 2 lists the quantitative results for

99 each condition i.e., the aspect ratio of the austenite grains, the volume fractions of

100 austenite and deformation induced martensite and the microstrain in austenite.

101 Assuming a direct relation between lattice defects and microstrain in austenite,

102 quantitative X-ray diffraction (XRD) analyses were used to determine the related

103

104

105

106

107

108

109

110

111 microstrain. TXRD measurements were performed by means of a Bruker AXS D8

diffractometer equipped with a $\mathrm{Co}$ Ka X ray tube with Goebel mirror opties and at

LynxEye linear position sentitive detector for ultra fast XRD measurements. Diffraction patterns were analyzed by Rietveld refinement using the TOPAS 4.2 software, where

the crystallographic information of each phase was obtained from Pearson's crystal structure database for inorganic compoundshe spectrums collected are shown in Figure 1.- As shown in Table 2, microstrain of austenite increases as deformation is raised. However, for deformation levels above the $35 \%$, deformation induced martensitic transformation also occurs. 
112 The volume percent of martensite induced by deformation in each sample was

113 quantified by XRD. Table 2 reveals that the higher the level of deformation, the higher

114 the volume percent of martensite. For the lowest level of deformation (15\%) no

115 martensite was detected in the XRD diffractogram (see Figure 1(b)), although the microstructure shows local traces of martensite (see Figure $21(\mathrm{~b})$ ), whose presence is

117 below the $3 \%$, which is the XRD experimental error.

118 An isothermal heat treatment in the pearlitic field were carried out in a Carbolite CTF

$11912 / 65 / 550$ furnace at $550^{\circ} \mathrm{C}$ for 1 hour followed by quenching in water in a sample

120 previously deformed at $35 \%$. Figure $\underline{4} 3$ (a) shows the pearlitic microstructure obtained,

121 revealing also the presence of martensite. The martensitic nature of the features

122 observed in Fig $\underline{43}$ (a) is consistent with the Electron backscatter diffraction (EBSD) analysis shown in Figure 43 (b). EBSD maps were collected at an acceleration voltage

124 of $20 \mathrm{kV}$ and collected using a CRYSTAL detector of Oxford Instruments mounted in a SEM JEOL JSM6300 microscope. EBSD maps were generated in areas of about

$126346 \times 282 \mu \mathrm{m}^{2}$ at step sizes of $0.45 \mu \mathrm{m}$. The indexation of the Kikuchi lines and the

127 determination of the orientations were done with the software CHANNEL 5 developed

128 by HKL Technology. Figure $\underline{4} 3$ (b) shows an IPF map where body-centered cubic (bcc)

129 martensite is represented by red pixels, and face-centered cubic (fcc) austenite is

130 represented by blue pixels. Additionally, Figure 43 (c) shows the microstructure

131 obtained after heat treatment of the area shown in Figure $\underline{43}$-a), consisting of pearlite

132 (dark etching areas) tempered martensite (light etching regions) and a mixture of

133 austenite and fresh martensite (white etching areas). Besides, Figure $\underline{4} 3$-(d) shows

134 details of the tempered martensite microstructure. 


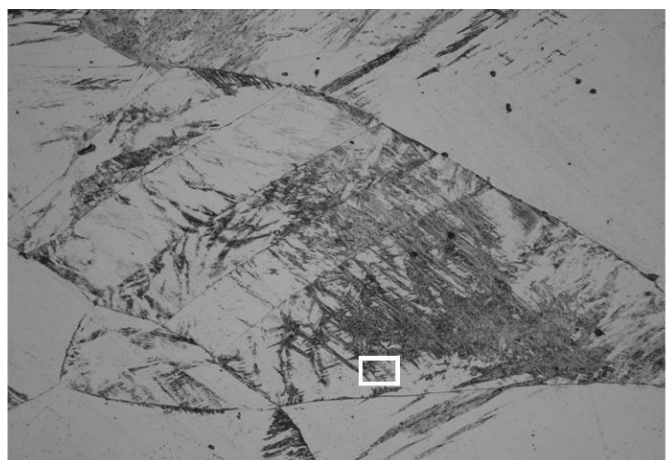

(a)

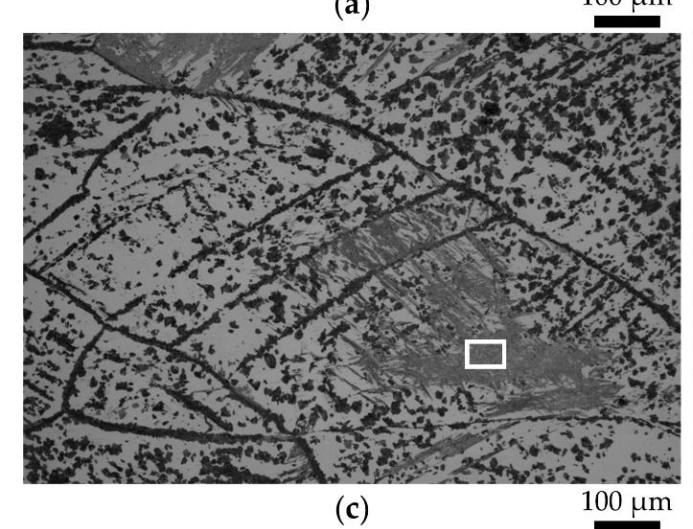

(c)

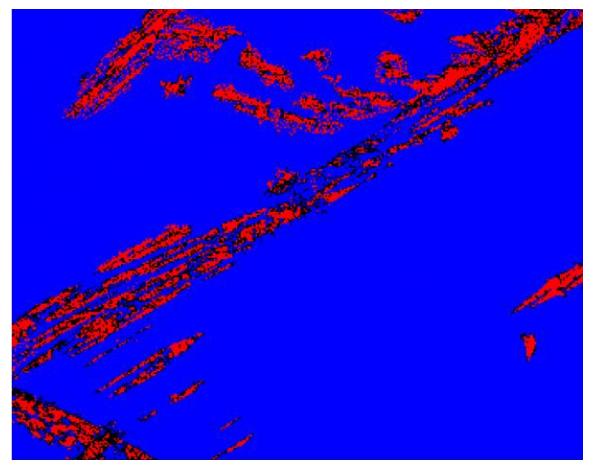

(b)

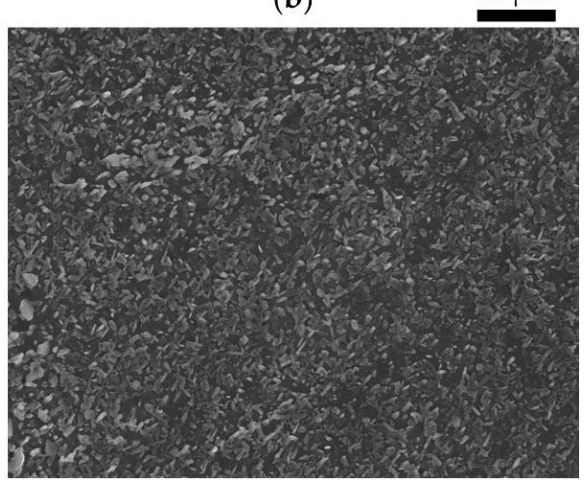

(d)
$1 \mu \mathrm{m}$

Figure 43. a) Austenitic and martensitic microstructure after deformation at 35\%, b)

EBSD Phase map. Red places represent BCC phase and blue places represent FCC phase. EBSD map was carry out in a samples deformed at $35 \%$ with an step size of 0.45 $\mu \mathrm{m}, \mathrm{c})$ same place of the microstructure a) after an isothermal treatment at $550^{\circ} \mathrm{C}$ for 1 hour in the pearlite field. d) SEM micrography of the tempered martensite obtained after the isothermal treatment.

137 Figure 54 demonstrates the role that the different lattice defects present in austenite 138 have in pearlite transformation. This figure shows an example of pearlite nucleated at

139 both twins and deformation bands. The decoration of austenite grain boundaries with

140 pearlite nodules is complemented with the intragranular nodules formed at lattice

141 defects. 


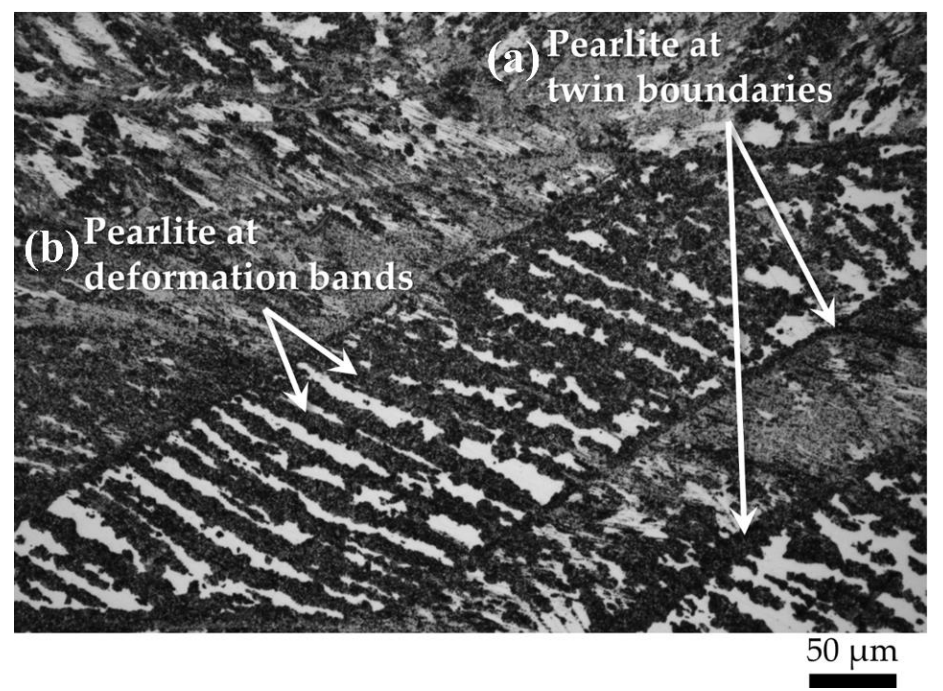

Figure 54 . Pearlite nucleated in a twin (a) and deformation bands (b)

144 Figure 65 shows optical micrographs of the samples transformed at $550{ }^{\circ} \mathrm{C}$ for 36 hours without prior deformation (Figure 65 (a)) and deformed at 15\%,35\%, 50\% and 70\% (Figure $\underline{6} 5-(\mathrm{b}), \underline{6} 5$-(c), $\underline{6}-$-(d) and $\underline{6} 5-(\mathrm{e})$, respectively). The white etching areas

147 correspond to austenite and/or fresh martensite, dark etching areas correspond to

148 pearlite, and light etching areas correspond to tempered martensite.

149 It is easy to see that the area percent of pearlite increases with the increase in the degree

150 of deformation. The area fraction of pearlite was evaluated on optical micrographs by

151 point counting method according to ASTM E562-02. For the sample deformed at 35\%,

152 tempered martensite regions were distinguished of pearlite by metallographic

153 procedures, and were therefore avoided in the evaluation of the pearlite area percent.

154 For high levels of deformation (50\% and 70\%) tempered martensite and pearlite areas

155 are interlocked, which makes it difficult to distinguish pearlite and determine its amount

156 by optical microscopy. Therefore, these two conditions were excluded from the study. 

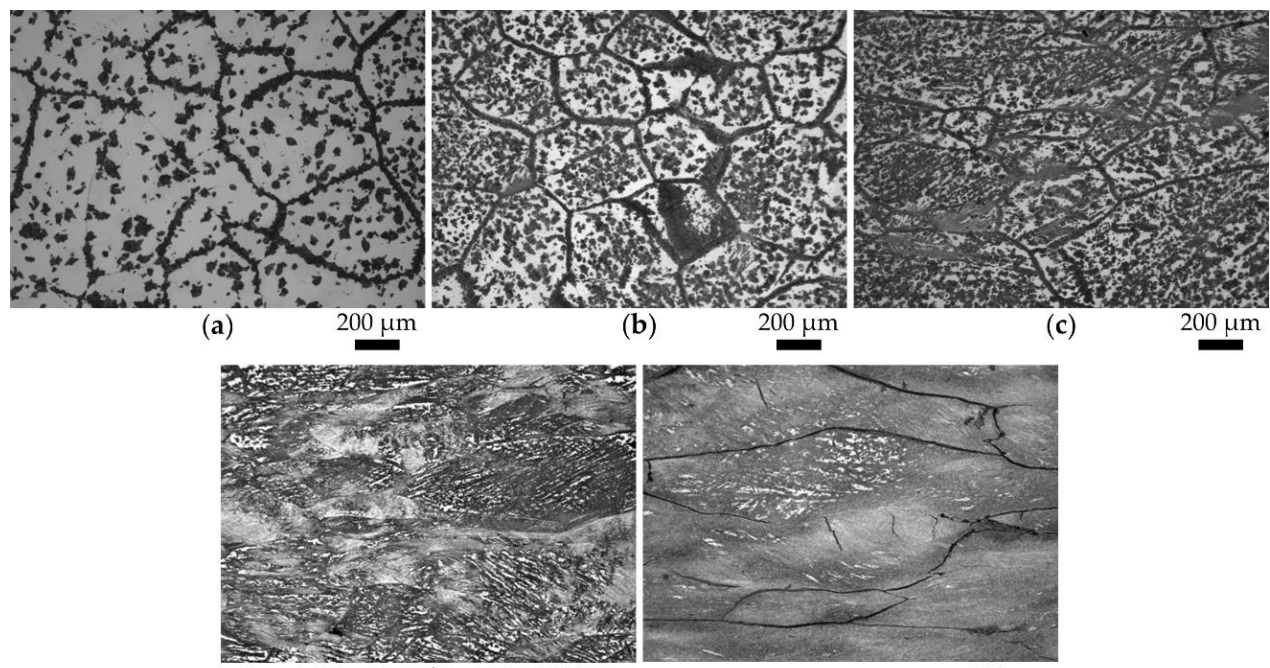

(d)
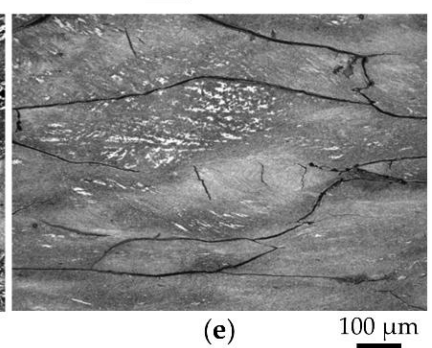

Figure 65 . Optical micrographs of the sample transformed at $550^{\circ} \mathrm{C}$ for 36 hours without previous deformation (a) and the samples previously deformed at 15\%, 35\%, 50\% and $70 \%$ (b, c, d and e respectively)

159 Figure 76 (a) shows the total area percent of pearlite as a function of the previous

160 deformation in austenite. Here, the higher the prior deformation of austenite is, the

161 higher the volume fraction of pearlite obtained for the same isothermal heat treatment.

162 The grain boundaries are, in all cases, covered by pearlite nodules. The evolution with

163 time of the size of these nodules is similar in all the samples, indicating that kinetics of

164 pearlite growth is not accelerated by prior austenite deformation. However, there is an

165 increase in the fraction of intragranular pearlite with the increase in the degree of the

166 deformation.

167 


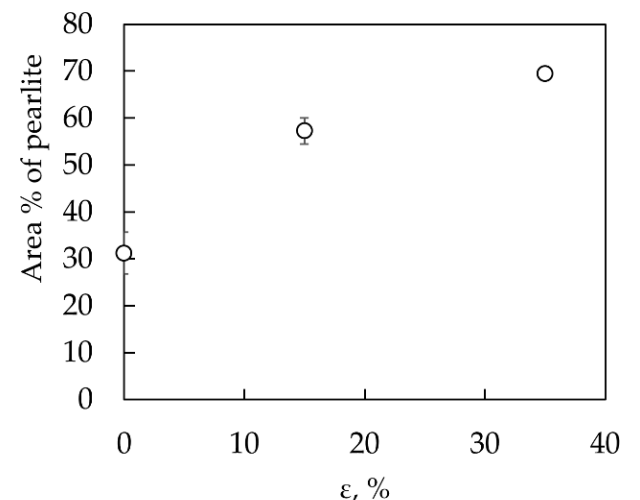

(a)

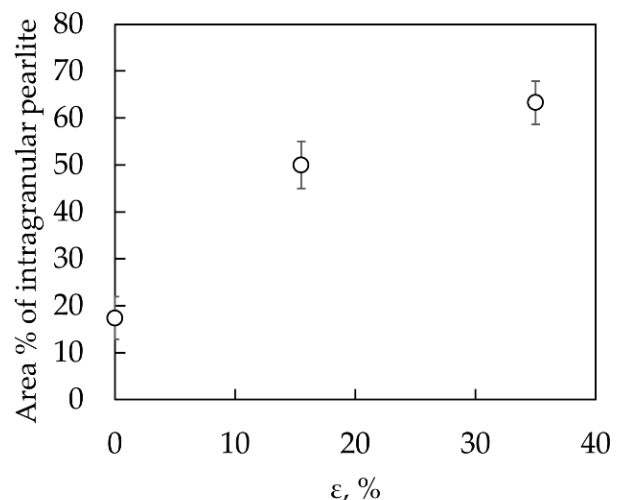

(b)

Figure 76 . (a) Total area fraction of pearlite, and (b) area fraction of intragranular pearlite as a function of the deformation.

169 The fraction of intragranular pearlite was measured on optical micrographs using

170 ImageJ software, excluding pearlite nucleated at grain boundaries and tempered

171 martensite regions. Figure 76 (b) shows the area fraction of intragranular pearlite as a

172 function of deformation of the austenite. The size of intragranularly formed pearlite

173 nodules presents a similar evolution with time as that of the size of pearlite nodules at

174 grain boundaries. Nevertheless, the number density of intragranular pearlite nodules

175 increases with the increase in the extent of prior austenite deformation.

176 The increase in the number of lattice defects, such as twins and deformation bands,

177 increases the number of nucleation sites for pearlite nodules, and hence, a higher

178 nucleation rate is obtained. In addition to increasing the density of heterogeneous

179 nucleation sites, the strain energy of the defects raises the austenite free energy, which

180 in turn leads to a specific reduction in the critical free energy for pearlite nucleation as it

181 was reported by Maalekian et al [129]. As a result, pearlite starts to nucleate earlier in

182 strained austenite as compared to pearlite nucleating in austenite without straining. 
The effect of the deformation in the morphology of pearlite was observed in SEM

191

192

$$
S_{V}^{P / P}=\frac{2 \cdot n_{r} \cdot M}{\pi \cdot d_{r}}
$$

194 Where $d_{r}$ is the diameter of the circumference, $n_{r}$ is the number of intersections with an edge of a colony and $\mathrm{M}$ is the magnification of the micrograph.

196

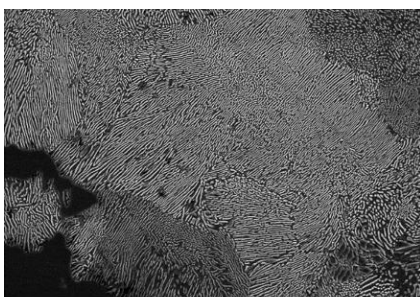

(a)

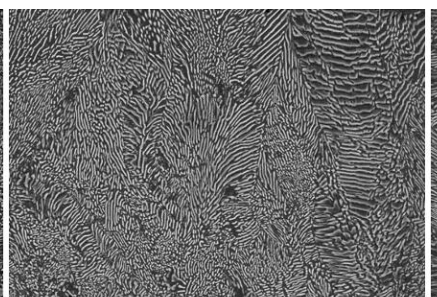

(b)

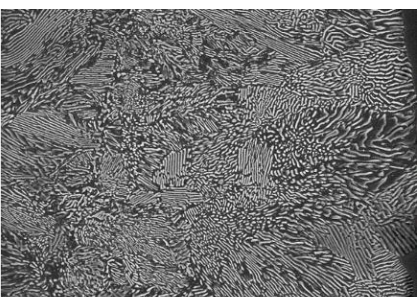

(c)

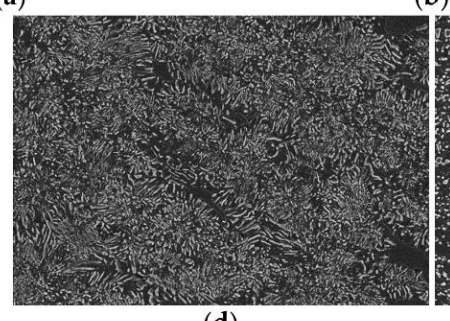

(d)

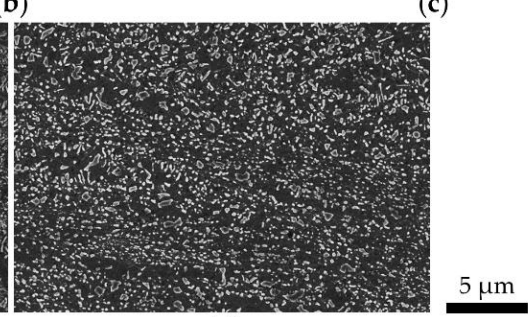

(e)

Figure 87 . SEM micrograhs of pearlite colonies of the samples previously deformed at.

a) $0 \%$ b) $15 \%$ c) $32 \%$ d) $50 \%$ and e) $70 \%$. Spherodized pearlite is shown in (d) and (e). 
198 Figure 98 shows the evolution of $S_{V}^{P / P}$ as a function of deformation of the austenite for

199 the samples transformed at $550^{\circ} \mathrm{C}$ for 36 hours. For high levels of deformation, the

200 austenite microstructure has a higher amount of lattice defects, and a refinement of the

201 colony size is observed. For samples deformed at $50 \%$ and $70 \%$, pearlite does not show

202 a laminar morphology, but a mixed morphology consisting in lamellar and spheroidal

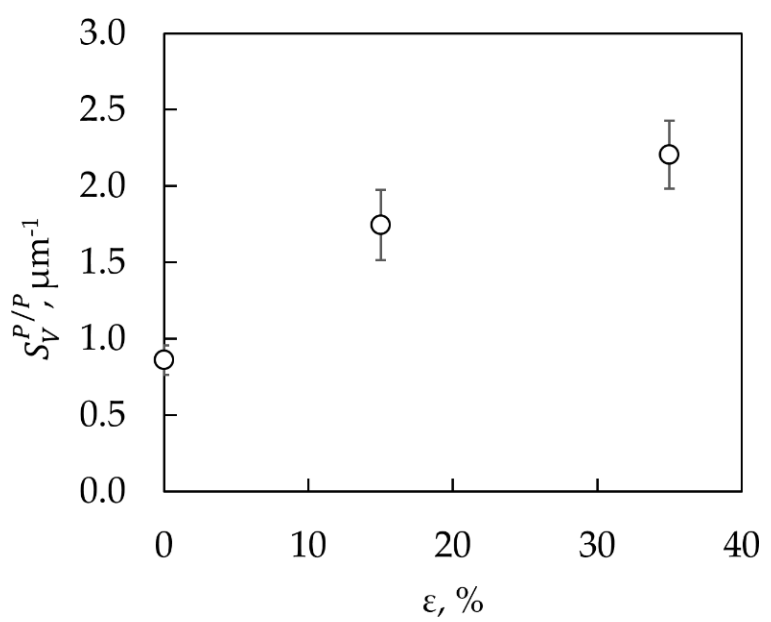

Figure 98 . Area per unit volume of the pearlite colony as a function of the previous deformation

208 As aforementioned, the increase in $S_{V}^{P / P}$ suggests an increase in the number of the 209 potential nucleation sites for pearlite. Once a pearlite colony is nucleated, pearlite

210 lamellae grow until another colony growing in the opposite direction is found. At this 211 point, the clamping of both occurs (hard impingement), and the growth of the colony 212 stops. Therefore, the increase in the number of potential intragranular nucleation sites 
213 by increasing the density of twins or deformation bands provides a colony size

214 refinement because of the hard impingement events on growing colonies. For higher

215 levels of deformation, such hard impingement events are so abundant that pearlite

216 colonies barely grow. This results in a pearlitic microstructure formed by short lamellae

217 of pearlite or just some nucleus of pearlite whose growth was so short that its geometric

218 form is closer to that of a particle than to that of a lamellar structure, providing a

219 microstructure of spheroidized morphology.

220 We might conclude that deformation of austenite prior to pearlite transformation

221 effectively accelerates the intragranular nucleation of pearlite through the nucleation at

222 twin boundaries and deformation bands. However, the increasing population of defects

223 not only increases the density of heterogeneous nucleation sites for pearlite

224 transformation, but also increases the austenite free energy due to strain. This fact leads

225 to a reduction in the critical free energy for pearlite nucleation, which triggers pearlite

226 formation as compared to austenite to pearlite transformation without straining. For the

227 case of highly strained austenite, the refinement of the pearlite colony size is so high that a spheroidized morphology of pearlite is obtained.

\section{Acknowledgments}

232 The authors acknowledge financial support to Spanish Ministerio de Economia y

233 Competitividad (MINECO) through in the form of a Coordinate Project (MAT2016-

234 80875-C3-1-R). Authors also acknowledge financial support to Comunidad de Madrid through DIMMAT-CM_S2013/MIT-2775 project. 
239 [1] J. Cahn, W. Hagel. Theory of the pearlite reaction. In: Z. Zackey, H. Aaronson,

240 editors. Decomposition of Austenite by Diffusional Processes. New York: Interscience, 241 1962. p.131-192.

242 [2] M. Hillert: New York: Interscience, 1962, vol., pp. 197-237.

243 [3] N. Ridley. The pearlite reaction. In: M.A. R., G. J.I, editors. Phase

244 Transformations in Ferrous Alloys. (TMS-AIME, Warrendale, PA): Metallurgical

245 Society of AIME, 1984. p.201-236.

246 [4] F.C. Hull, R.F. Mehl: Trans. ASM, 1942, vol. 30, pp. 381-421.

247 [5] H.I. Aaronson, V.F. Zackay: Decomposition of austenite by diffusional 248 processes. Interscience Publ., 1962, p. Pages.

249 [6] P.J. Clemm, J.C. Fisher: Acta Metall_urgica, 1955, vol. 3, pp. 70-73.

250 [7] T. Furuhara, N. Kimura, T. Maki: $\underline{\text { S}}$ steel Rfes_earch Iint.ernationat, 2012,10.1002/srin.201100305, vol. 83, pp. 358-362.

252 [8] M. Umemoto, H. Ohtsuka, I. Tamura: Trans.actions of the Iron and-Steel Inst.itute of Japan, 1983, vol. 23, pp. 775-784.

254 [9] J. Moon, S. J-. Park, J. H. Jang, T. H-. Lee, C. H-. Lee, H. U-. Hong, H. N. Han, J. Lee, B. H. Lee, C. Lee: Acta Mater_ialia, 2018, vol. 147, pp. 226-235.

[11] S. Chen, R. Rana, A. Haldar, R. K. Ray: Prog_ress in Mater_ials Sci_ence, vol. $89,345-391$.

259 [12] M. Maalekian, M.L. Lendinez, E. Kozeschnik, H.P. Brantner, H. Cerjak: Mater. Sci. Eng. A, 2007, vol. 454-455, pp. 446-452. 
261 [13] M. Hillert. The formation of pearlite. In: V.F. Zackay, H.I. Aaronson, editors.

262 Decomposition of austenite by diffusional processes. New York: Interscience,

263

264

265 1962. p.197-237.

[14] E.E. Underwood, J.C. Grebetz, R.A. Koos. STATISTICAL STUDY OF GRAPHITE AND PEARLITE IN NODULAR CAST IRON. Praktische Metallographie/Practical Metallography, vol. 19, 1982. p.347-355. 
Figure Captions

269 Figure 1: XRD spectrums of (a) As-received microstructure; (b) after 15\% deformation, $15 \%(\mathrm{~b}), 35 \%(\mathrm{c}), 50 \%(\mathrm{~d})$ and $70 \%(\mathrm{e})$.

274 promotes in the austenitic microstructure by deformation at $35 \%$. EBSD Phase map. Red places represent BCC phase and blue places represent FCC phase. EBSD map was carry out in a samples deformed at $35 \%$ with an step size of 0.45

$278 \mu \mathrm{m}, \mathrm{c})$ same place of the microstructure a) after an isothermal treatment at $550^{\circ} \mathrm{C}$ for 1

279 hour in the pearlite field. d) SEM micrography of the tempered martensite obtained after

280 the isothermal treatment.

281 Figure 54. Pearlite nucleated in a twin (a) and deformation bands (b)

283 previous deformation (a) and the samples previously deformed at 15\%, 35\%, 50\% and

$28470 \%$ (b, c, d and e respectively) pearlite as a function of the deformation.

287 Figure $\underline{87}$. SEM micrograhs of pearlite colonies of the samples previously deformed at. a) $0 \%$ b) $15 \%$ c) $32 \%$ d) $50 \%$ and e) $70 \%$. Spherodized pearlite is shown in (d) and (e).

289 Figure 98. Area per unit volume of the pearlite colony as a function of the previous deformation 
Table 1: Chemical composition (in wt\%) of TRIP/TWIP steel studied

\begin{tabular}{|l|l|l|l|l|}
\hline & C & Mn & Al & Fe \\
\hline Wt. $\%$ & 0.63 & 9.82 & 4.60 & Balance \\
\hline
\end{tabular}

Table 2. Aspect ratio, volume fraction of martensite, volume fraction of austenite and

299 microstrain austenite as a function of the deformation.

\begin{tabular}{|c|c|c|c|c|c|}
\hline Deformation & $0 \%$ & $15 \%$ & $35 \%$ & $50 \%$ & $70 \%$ \\
\hline Aspect ratio & $0.77 \pm 0.09$ & $0.67 \pm 0.14$ & $0.55 \pm 0.15$ & $0.31 \pm 0.08$ & $1.54 \pm 0.42$ \\
\hline $\begin{array}{l}\text { Volume } \\
\text { fraction } \\
\text { Martensite }\end{array}$ & $0 \pm 3$ & $0 \pm 3$ & $7.2 \pm 3$ & $27.6 \pm 3$ & $47.9 \pm 3$ \\
\hline $\begin{array}{l}\text { Volume } \\
\text { fraction } \\
\text { austenite }\end{array}$ & $100 \pm 3$ & $100 \pm 3$ & $92.8 \pm 3$ & $72.4 \pm 3$ & $51.5 \pm 3$ \\
\hline $\begin{array}{l}\text { Microstrain } \\
\text { austenite }\end{array}$ & 0.035 & 0.096 & 0.12 & 0.14 & 0.24 \\
\hline
\end{tabular}

300

301 